\title{
Assessing the Relative Role of Climate and Human Activities on Vegetation Cover Changes in the Up- down Stream of Danjiangkou, China
}

Hai Liu

Hubei University

Hongmeng Yuan

Hubei University

Liang Zheng (D 1241580102@qq.com)

Wuhan University

Yuan Zhang

Environmental monitoring center station of hubei province

\section{Research}

Keywords: Remote sensing monitoring, NDVI, Climate change, Urban expansion, Returning farmland to forest

Posted Date: February 3rd, 2021

DOI: https://doi.org/10.21203/rs.3.rs-184024/v1

License: (9) This work is licensed under a Creative Commons Attribution 4.0 International License. Read Full License

Version of Record: A version of this preprint was published at Journal of Plant Ecology on August 5th, 2021. See the published version at https://doi.org/10.1093/jpe/rtab082. 
Assessing the relative role of climate and human activities on vegetation cover changes in the Up-Down stream of Danjiangkou,

\section{China}

Hai Liu ${ }^{1}$, Hongmeng Yuan ${ }^{1}$, Liang Zheng ${ }^{2 *}$, and Yuan Zhang ${ }^{3}$

${ }^{1}$ Hubei University, Faculty of resources and environment Science, Wuhan Hubei, 430062, China;

2 Wuhan University, State Key Laboratory of Information Engineering in Surveying, Mapping and Remote Sensing, Wuhan 430079, China

${ }^{3}$ Environmental monitoring center station of Hubei province, Wuhan 430071, China

*Correspondence:1241580102@qq.com

Received: date; Accepted: date; Published: date 


\section{Assessing the relative role of climate and human activities on \\ 2 vegetation cover changes in the Up-Down stream of Danjiangkou, 3 China}

4 Abstract : Danjiangkou Reservoir is water source of Middle Route Project of the South-to-

5 North Water Diversion (SNWD) Project, research on the dynamic changes in vegetation cover and its influencing factors is of great significance for understanding the ecological environment of the water diversion area and formulating protection measures. In this study, The normalized difference vegetation index (NDVI) was used to analyze the dynamic changes and influencing factors of vegetation in the upstream and downstream of Danjiangkou Dam from 1982 to 2018. The results show that the NDVI shows an upward trend of 0.017 year $^{-1}(\mathrm{P}<0.05)$, and the significantly increased area is located near the valley upstream of the dam, while the significantly decreased area is mainly distributed in the basin downstream of the dam and around the central city. The comprehensive contributions of climate and human activity factors to NDVI changes were $92.03 \%$ and $7.97 \%$, respectively.The human activities in the upstream of the dam are mainly reflected in the ecological measures such as returning farmland to forest; the human activities at the downstream of the dam are mainly reflected in urban expansion, occupation of cultivated land and forest land by construction land.

Keywords: Remote sensing monitoring; NDVI; Climate change; Urban expansion; Returning farmland to forest 


\section{Introduction}

As climate change and human activities continue to intensify, the global natural ecosystem has been seriously threatened1. Vegetation constitutes a major part of terrestrial ecosystems ${ }^{2}$ and plays a key role in the flow of matter and energy among the pedosphere, hydrosphere and atmosphere ${ }^{3-4}$. Monitoring and attribution analysis of vegetation changes is of vital importance to global climate change and the creation of environmental policies ${ }^{5-8}$.

Due to large interannual variability, spatial patterns of vegetation change trends and their drivers may vary substantially in different areas when different study periods are selected. Therefore, monitoring and analysis of large-scale and long-term vegetation changes has become an important part of global change research ${ }^{9}$. The rapid development of remote sensing technology has provided effective ways to study vegetation cover changes at large scales and a variety of remote sensing data sources to monitor vegetation cover change ${ }^{10} . \mathrm{NDVI}^{11}$ has a linear or near-linear relationship with green leaf density, photosynthetically active radiation, vegetation productivity and cumulative biomass, which is recognized as an effective index to reflect the vegetation coverage and growth status on a large scale ${ }^{12-14}$. With increasing concern over global climate change, there is much interest in the relationship between terrestrial ecosystems and global climate change ${ }^{15-16}$. According to previous studies, precipitation and temperature are considered to be key climatic factors affecting plant growth and development, and they are both significant in impacting vegetation variation with high spatial and temporal heterogeneity ${ }^{17-18}$. With the increasing 
interference of human activities on nature, many studies have gradually concluded that human-induced activities are the important factors affecting the ecological environmen (Flood susceptibility ${ }^{19}$, Desertification ${ }^{20}$, Lake inundation area $^{21}$ ). The impact of human activities on changes in vegetation coverage has two sides. The development of urbanization has caused a large amount of farmland and forestland to be occupied by construction land, which has significantly reduced the coverage of vegetation $^{22-23}$. The implementation of vegetation construction projects such as returning farmland to forest and grass is conducive to the increase of vegetation coverage $^{24-25}$, studies have shown that the nonclimatic factors that have the greatest impact on vegetation in China are various forestry projects aimed at improving vegetation coverage ${ }^{26}$. Land use can reflect the extent of human activities on the surface of land to a certain degree, many scholars study human activities by land use change ${ }^{19,27}$. To deeply understand the drivers of vegetation change, it is urgent to identify, separate and evaluate the relative role of climate change and human activities in vegetation cover change. In recent years, many methods have been used to quantitatively separate the relative role of climate change and human activities, such as the Principal Component Analysis method ${ }^{28}$, Residual Trends method ${ }^{29-30}$, Regression model method ${ }^{31}$. Comparatively, the Residual Trends method are based on the long time series of land surface vegetation information, having the advantages of separating and quantifying the relative role of climate change and human activities and being suitable for different spatial and temporal scales. In addition, the Residual Trends method is a helpful tool that can effectively identify human-induced 
degradation, combined with the theoretical trend of NDVI to evaluate the relative roles of climate change and human activities ${ }^{32-33}$.

The Danjiangkou Reservoir is the source of water for the strategic Middle Route Project of the South-North Water Transfer Project. The South-North Water Transfer Project is a major interbasin water transfer project in $\mathrm{China}^{34}$; the construction was started in 2003, and the first phase was finished in 2013. The water transfer project will greatly reduce the amount of water resources available downstream of the dam and will affect the ecological environment of the upper and lower reaches of the Hanjiang River basin where the dam is located ${ }^{35}$. To ensure the water quality and quantity of the core water source area and the water safety of the South-to-North Water Transfer Project, many ecological protection policies have been implemented upstream of the dam in recent years, while large and medium-sized cities are distributed downstream of the dam, with rapid economic development. There are great differences between the upstream and downstream dam areas in terms of social and economic development and policy systems. The study of vegetation change and its influencing factors upstream and downstream of dams is of great significance for understanding the ecological environment and formulating protection measures in water diversion areas. At present, some scholars have studied the vegetation cover changes upstream and downstream of the Danjiangkou Dam ${ }^{36-38}$.

Despite their outstanding scientific value, long-term analysis is lacking due to the influence of the spatial-temporal resolution of remote sensing data. Additionally, there are few quantitative analysis studies on the impact of human activities on 
vegetation changes, especially the comparative analysis of upstream and downstream areas. Therefore, the purpose of this paper is to evaluate the long-term (1982-2018) vegetation dynamic changes in the upper and lower reaches of the Danjiangkou Dam and the impact of climate and human activities on them. The specific objectives of this study are as follows: (1) construction of a long-term series high-resolution NDVI dataset; (2) quantitative analysis of the impact of climate and human activities on regional vegetation changes; and (3) comparative analysis of upstream and downstream human activities.

\section{Data and Methodology}

\section{Study area}

The Han River, where the Danjiangkou Dam $\left(32^{\circ} 36^{\prime}-33^{\circ} 48^{\prime} \mathrm{N} ; 110^{\circ} 59^{\prime}-111^{\circ} 49^{\prime} \mathrm{E}\right)$ is located, is the largest tributary of the Yangtze River (Fig. 1). The Han River flows through the provinces of Shaanxi, Henan and Hubei, with a total length of 1,532 km and a drainage area of approximately 150,700 square kilometers. The Danjiangkou Dam is the dividing point between the upper and lower reaches of the Hanjiang River Basin. Above the dam is the upstream region, and below the dam is the downstream region. The Hanjiang River Basin belongs to the East Asian subtropical monsoon climate zone. The four seasons are distinct, the climate is mild and humid, and water is abundant. The annual average temperature is $16^{\circ} \mathrm{C}$, and the annual average precipitation is $900.4 \mathrm{~mm}$. The elevations of the upper and lower reaches of the basin are quite different, with a maximum of nearly $3000 \mathrm{~m}$ and a minimum of $10 \mathrm{~m}$. 

margins of the basin, the surface undulations are relatively low, and the ground is relatively flat.

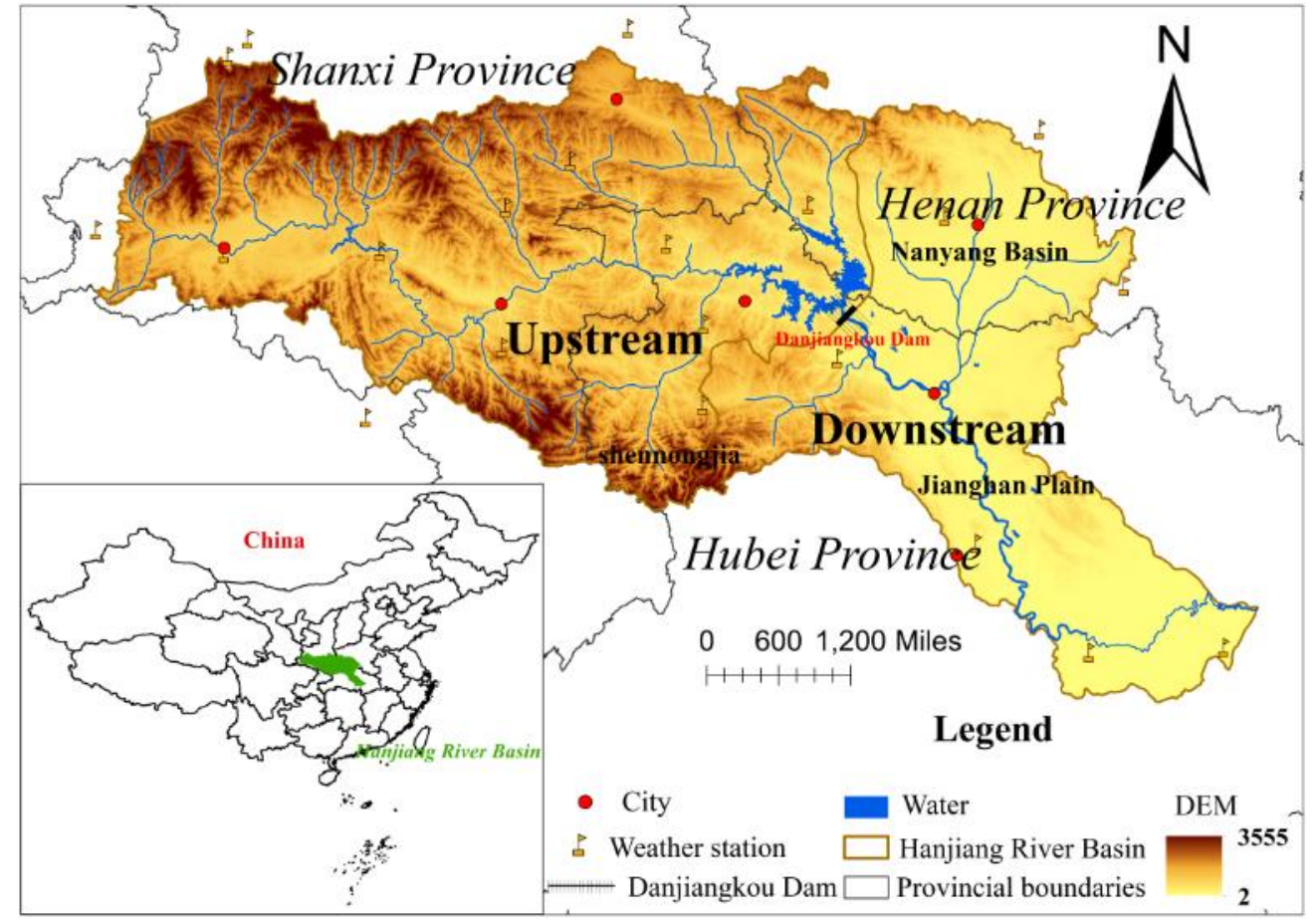

Figure. 1 Location of the Danjiangkou Dam (The map was created using ESRI ArcGIS 10.3, http://www.esri.com/sofware/arcgis/arcgis-for-desktop).

\section{Data}

\section{NDVI data}

The Moderate Resolution Imaging Spectroradiometer (MODIS) NDVI and Global Inventory Modelling and Mapping Studies (GIMMS) NDVI datasets are all from the National Aeronautics and Space Administration

(NASA) (https://ladsweb.modaps.eosdis.nasa.gov/). We selected MOD13Q1 from MODISTerra, which includes NDVI data from 2000 to the present with a temporal resolution 
of 16 days and a spatial resolution of $250 \mathrm{~m} \times 250 \mathrm{~m}^{39}$.

MODIS is only available from 2000, so the data cannot support long-term vegetation cover change research. Considering that the data were incomplete in 2000, we selected data from 2001-2018 for research.

The GIMMS data from the Advanced Very High Resolution Radiometer (AVHRR) sensor. AVHRR provides remote sensing data from July 1981 to present ${ }^{40}$. The GIMMS NDVI data set is also the longest, most complete and most widely used AVHRR time series data set at present ${ }^{41}$. The GIMMS NDVI data set is derived from the latest global vegetation index change data released by NASA in November 2003. The data set includes the global vegetation index change from 1981 to 2006. Its temporal resolution is 15 days, and its spatial resolution is $8 \mathrm{~km} \times 8 \mathrm{~km}$. Since the data were incomplete in 1981, we selected data from 1982 to 2006 for research.

The MODIS NDVI and GIMMS NDVI data are combined into monthly NDVI data by using the maximum value composite (MVC) method, and the monthly NDVI data are synthesized into annual average NDVI data by using the MVC method. The MVC method chooses the maximum data of each pixel at multiple times to represent the current NDVI value ${ }^{42}$.

\section{Other data}

The meteorological data are based on site data pertaining to the monthly mean temperature and monthly precipitation provided by the China Meteorological Data Service Center (CMDC). The CMDC is a governmental and unified shared service platform of the China Meteorological Administration, and its meteorological data 
resources are open to domestic and global users. There are 21 meteorological stations upstream and downstream of the Danjiangkou Dam (Fig. 1). The monthly average temperature and precipitation data of the meteorological stations from 1982 to 2018 are obtained in this study. Considering the longitude, latitude and elevation of the meteorological stations, the spatial distribution data of the average temperature and precipitation are obtained by ordinary kriging interpolation, and the spatial resolution of the grid after interpolation is $1 \mathrm{~km}$. The monthly temperature data after interpolation are averaged to obtain the annual average temperature, and the monthly precipitation data after interpolation are summed to obtain the annual precipitation.

The land use data are derived from the China National Earth System Science Data-Sharing Platform (www.geodata.cn). With the support of the China Science and Technology Support Program and important direction from the knowledge innovation project of the Chinese Academy of Sciences, this data set is generated by manual visual interpretation with Landsat TM/ETM remote sensing images as the main data source. Land use types include six first-class types of cultivated land, forests, grassland, water, construction land and unutilized land, and 25 second-class types, with a resolution of $1 \mathrm{~km}$. Due to the lack of data from 1982, we selected 1980 as the starting year to analyze the changes in land use types upstream and downstream of the dam from 1980 to 2018.

\section{Methodology}

\section{EOT model}

van den Dool et al. ${ }^{43}$ proposed a new algorithm based on the empirical orthogonal 
function(EOF) algorithm for calculating empirical orthogonal functions from a given

167 spatiotemporal data set. This method is based on multivariate linear regression to 168 obtain an orthogonal solution in one direction (space or time) to emphasize its 169 similarity with EOF, named the empirical orthogonal teleconnections(EOT) 170 algorithm. The mathematical principle of the EOT algorithm is as follows: Suppose 171 we have a discrete space-time $(\mathrm{s}, \mathrm{t})$ dataset $\mathrm{T}(\mathrm{s}, \mathrm{t}), 1 \leq \mathrm{t} \leq \mathrm{nt}, 1 \leq \mathrm{s} \leq \mathrm{ns}$, where $\mathrm{T}$ 172 denotes the variable (such as height, pressure, streamfunction, etc.). EOT is a stepwise linear regression, where the predictands are $\mathrm{T}(\mathrm{s}, \mathrm{t})$, and the predictors are $\mathrm{T}(\mathrm{s}, \mathrm{t})$. One can search all $\mathrm{s}$ for that point in space (sb; abase point) that explains most of the variance at all other points (including itself) combined. What is explained by $\mathrm{T}(\mathrm{sb}, \mathrm{t})$ is removed from $\mathrm{T}(\mathrm{s}, \mathrm{t})$ by standard regression, and one can then search the reduced data for the next most important (in terms of variance explaining) point in space, and so on. Through this process, one eventually obtains : where $\alpha \mathrm{m}(\mathrm{t})$ is a time series, $\mathrm{em}(\mathrm{s})$ is a spatial pattern, $\mathrm{m}=1 \ldots, \mathrm{ns}$. Based on the theoretical background of EOT, Appelhans et al. ${ }^{44-45}$ have implemented the EOT algorithm efficiently in the open source software package remote for R, which expands the application scope of the EOT algorithm. The open source package of the EOT algorithm is available from the R Comprehensive Archive

Network (http://CRAN.R-project.org/package=remote.)

We select GIMMS NDVI and MODIS NDVI overlapping period data (2001- 
model training, and the data from 2005 to 2006 are used for verification. Using the EOT algorithm, we reconstructed the GIMMS NDVI data with a resolution of $8 \mathrm{~km}$ from 1982 to 2006 to the EOT NDVI dataset with a resolution of $1 \mathrm{~km}$ and resampled the 2007-2018 $250 \mathrm{~m}$ resolution MODIS NDVI dataset to a $1 \mathrm{~km}$ resolution. The NDVI dataset with a resolution of $1 \mathrm{~km}$ from 1982 to 2018 was finally obtained.

\section{Trend analysis}

In this study, based on the linear regression method, the temporal fluctuations in the temperature, precipitation and annual average NDVI are analyzed. The linear regression relationship between year (i) and NDVI $\left(\mathrm{X}_{\mathrm{i}}\right)$ is established by using the ordinary least squares (OLS) slope in space, and the spatial variation in the annual average NDVI is analyzed. The slope of the OLS curve is as follows:

$$
\theta_{\text {slop }}=\frac{\mathrm{n} \times \sum_{\mathrm{i}=1}^{\mathrm{n}} \mathrm{i} \times \mathrm{X}_{\mathrm{i}}-\sum_{\mathrm{i}=1}^{\mathrm{n}} \mathrm{i} \sum_{\mathrm{i}=1}^{\mathrm{n}} \mathrm{X}_{\mathrm{i}}}{\mathrm{n} \times \sum_{\mathrm{i}=1}^{\mathrm{n}} \mathrm{i}^{2}-\left(\sum_{\mathrm{i}=1}^{\mathrm{n}} \mathrm{i}\right)^{2}}
$$

where the regression coefficient $\theta_{\text {slop }}$ represents the trend of variable $\mathrm{X}_{\mathrm{i}}, \mathrm{i}$ represents the year, $X_{i}$ represents the NDVI value in corresponding year $i$, and $n$ is the research period. $\theta_{\text {slop }}>0$ indicates an increasing trend of the NDVI, and $\theta_{\text {slop }}<0$ indicates a decreasing trend of the NDVI. The F test was used to test the significance of the NDVI change.

\section{Correlation analysis}

Partial correlation analysis is used to measure the degree of linear correlation between two variables among multiple variables under the condition of controlling the influences of the other variables, which can effectively eliminate the influences of the 
other variables, and the method is more reliable when determining the intrinsic linear relationship between two variables. Therefore, we conduct partial correlation analysis to calculate the relationship between the two variables. The partial correlation equation is as follows:

$$
\mathrm{r}_{\mathrm{ab}, \mathrm{c}}=\frac{\mathrm{r}_{\mathrm{ab}}-\mathrm{r}_{\mathrm{ac}} \times \mathrm{r}_{\mathrm{bc}}}{\sqrt{\left(1-\mathrm{r}_{\mathrm{ac}}{ }^{2}\right) \times\left(1-\mathrm{r}_{\mathrm{bc}}{ }^{2}\right)}}
$$

where $\mathrm{a}$ is NDVI, $\mathrm{b}$ is precipitation, $\mathrm{c}$ is temperature, $\mathrm{r}_{\mathrm{ab}} \mathrm{c}$ denotes the partial correlation coefficient between variables $\mathrm{a}$ and $\mathrm{b}$ when $\mathrm{c}$ is the control variable, $\mathrm{r}_{\mathrm{ab}}, \mathrm{r}_{\mathrm{ac}}$ and $\mathrm{r}_{\mathrm{bc}}$ denote the correlation coefficients between variables $\mathrm{a}$ and $\mathrm{b}$, $\mathrm{a}$ and $\mathrm{c}$, and $\mathrm{b}$ and $c$, respectively, and the range of $r_{a, b, c}$ values is -1 to 1 . When $r_{a b, c}<0$, variables a and $\mathrm{b}$ have a negative correlation, and when $\mathrm{r}_{\mathrm{ab}, \mathrm{c}}>0$, variables $\mathrm{a}$ and $\mathrm{b}$ exhibit a positive correlation. A t-significance test was used to evaluate the correlation results. The equation of the significance test was as follows:

$$
\mathrm{t}=\frac{\mathrm{r}_{\mathrm{ab}, \mathrm{c}} \sqrt{\mathrm{n}-\mathrm{k}-2}}{\sqrt{1-\mathrm{r}_{\mathrm{ab}, \mathrm{c}}^{2}}}
$$

In the equation above, $\mathrm{t}$ is the test statistic, $\mathrm{n}$ is the number of samples, and $\mathrm{K}$ is the number of control variables (1 here).

\section{Residual Trends method}

Residuals are the differences between actual observed values and the predicted (regression) values ${ }^{46}$. We used residual analysis to quantify the impact of human effects on vegetation growth, i.e., by establishing the regression model between NDVI and natural factors, the prediction value of NDVI can be obtained based on the existing natural factor data, and then it can be subtracted from the remote sensing 
observation of NDVI to determine the annual residual value of NDVI, which can reflect the impact of human activities on vegetation growth. In this study, we predict the impact of human activities by establishing regression relationships among precipitation, temperature and NDVI. The expression of residual analysis is as follows:

where $\alpha$ and $\beta$ are regression coefficients of the NDVI for precipitation and air temperature; $\lambda$ is the regression constant term; $\mathrm{P}$ and $\mathrm{T}$ represent precipitation and temperature, respectively; NDVIreal is the true NDVI value; NDVIpre is the predicted NDVI value; $\varepsilon>0$ indicates that human activities have a positive impact; $\varepsilon<$ 0 indicates that human activities have a negative impact; and $\varepsilon=0$ indicates that human activities have a slight impact. The specific steps are as follows: precipitation, and temperature.

(3) Based on the existing precipitation and temperature data, $\alpha$ and $\beta$ are substituted in the linear regression model to predict the vegetation coverage. value to obtain the residual NDVI value.

(4) Subtract the predicted NDVI value from the remote sensing image NDVI and human activities to the NDVI can be further distinguished. The overall 

application in spatial resampling.

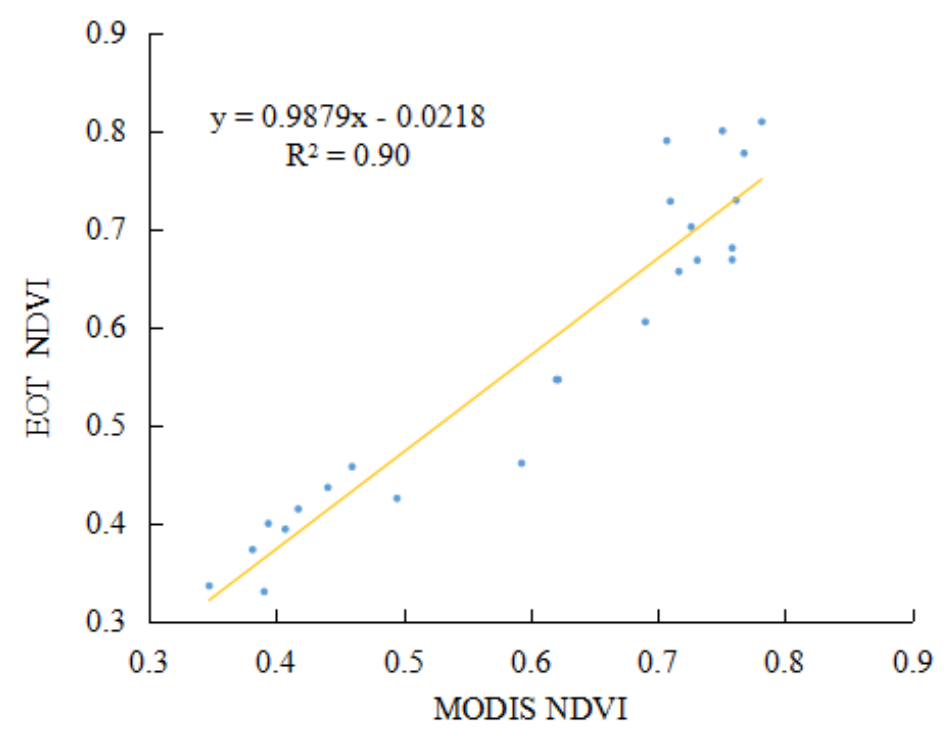

contribution of human activities to the NDVI is:

$$
C H=|\varepsilon| / N D V I_{\text {real }} \times 100 \%
$$

The overall contribution of natural factors to the NDVI is:

$$
C N=1-C H
$$

\section{Results}

\section{Long-term NDVI data}

Based on MODIS NDVI observed monthly data and predicted $1 \mathrm{~km}$ resolution EOT NDVI monthly data (2005-2006), we calculated the error coefficient $(\mathrm{ME}=0.029$; MAE $=0.045 ;$ RMSE $\left.=0.057 ; R^{2}=0.904\right)$. In summary, the error between the NDVI predicted by the EOT model and the observed value of remote sensing data is relatively small, and the high $\mathrm{R}^{2}$ value (Fig. 2) verifies the good agreement between the predicted GIMMS NDVI and MODIS NDVI and supports EOT algorithm

Figure 2 Verification of EOT NDVI and MODIS NDVI from 2005 to 2006 
268 Figure 3 shows the interannual change in the area-averaged NDVI for the period of 1982-2018. The area-averaged NDVI significantly increased at a rate of 0.017 year-1 ( $p<0.05$, Fig. 3). The area-averaged NDVI minimum value appeared in 2000, and the

271 maximum value appeared in 2015. The trend of the area-averaged NDVI change 272 fluctuated greatly before 2001, and the area-averaged NDVI change trend fluctuated 273 slightly after 2001.

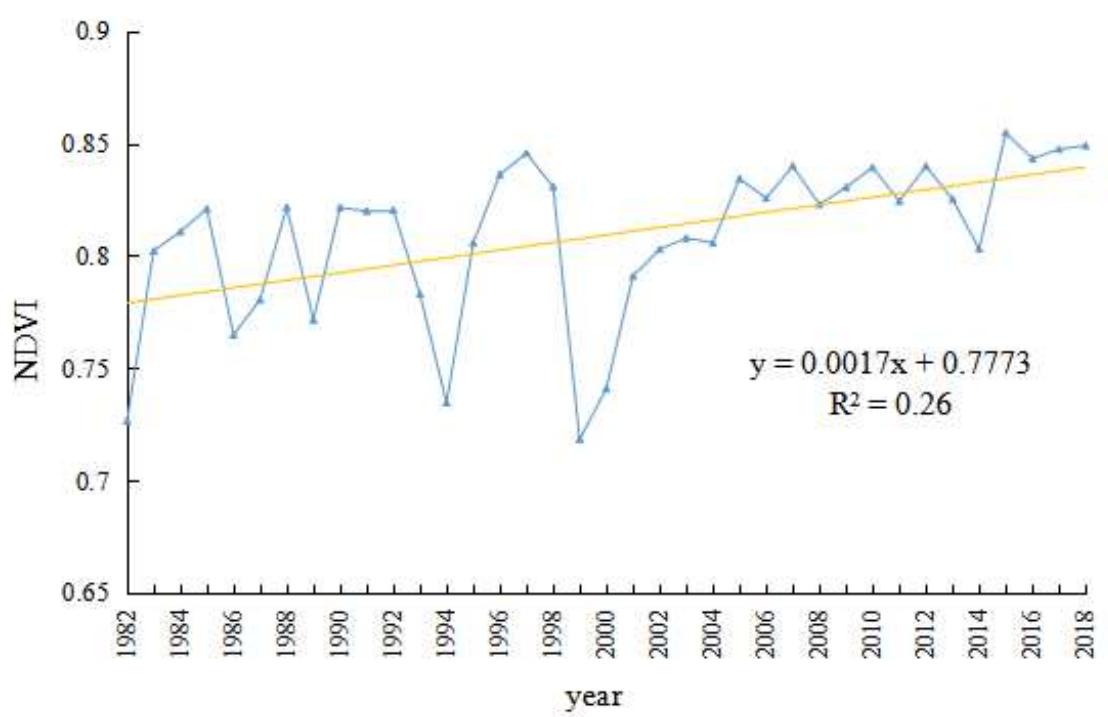

Figure. 3 Annual average NDVI trends from 1982 to 2018

On the pixel scale, NDVI change trend patterns from 1982 to 2018 were spatially

$75.88 \%$ of the pixels showed an increasing trend $(68.54 \%$ significantly with $\mathrm{p}<0.05)$, mainly located around the river upstream of the dam; $24.12 \%$ of the pixels showed a decreasing trend $(25.42 \%$ significantly with $\mathrm{p}<0.05)$, mainly located in the basin downstream of the dam and around the central city. 
significantly with $\mathrm{p}<0.05$ ), mainly located around the river; $10.07 \%$ of the pixels showed a decreasing trend $(7.79 \%$ significantly with $p<0.05)$, mainly located around the central city. Downstream of the dam, $54.52 \%$ of the pixels showed an increasing trend $(50.06 \%$ significantly with $\mathrm{p}<0.05)$, mainly distributed in the periphery of the basin; $45.48 \%$ of the pixels showed a decreasing trend (31.44\% significantly with $\mathrm{p}<$ 0.05), mainly located in Nanyang basin and around the central city.

In summary, the change in NDVI upstream of the dam is mainly reflected in a significant increasing trend, and the change in NDVI downstream of the dam is mainly reflected in a significant decreasing trend.

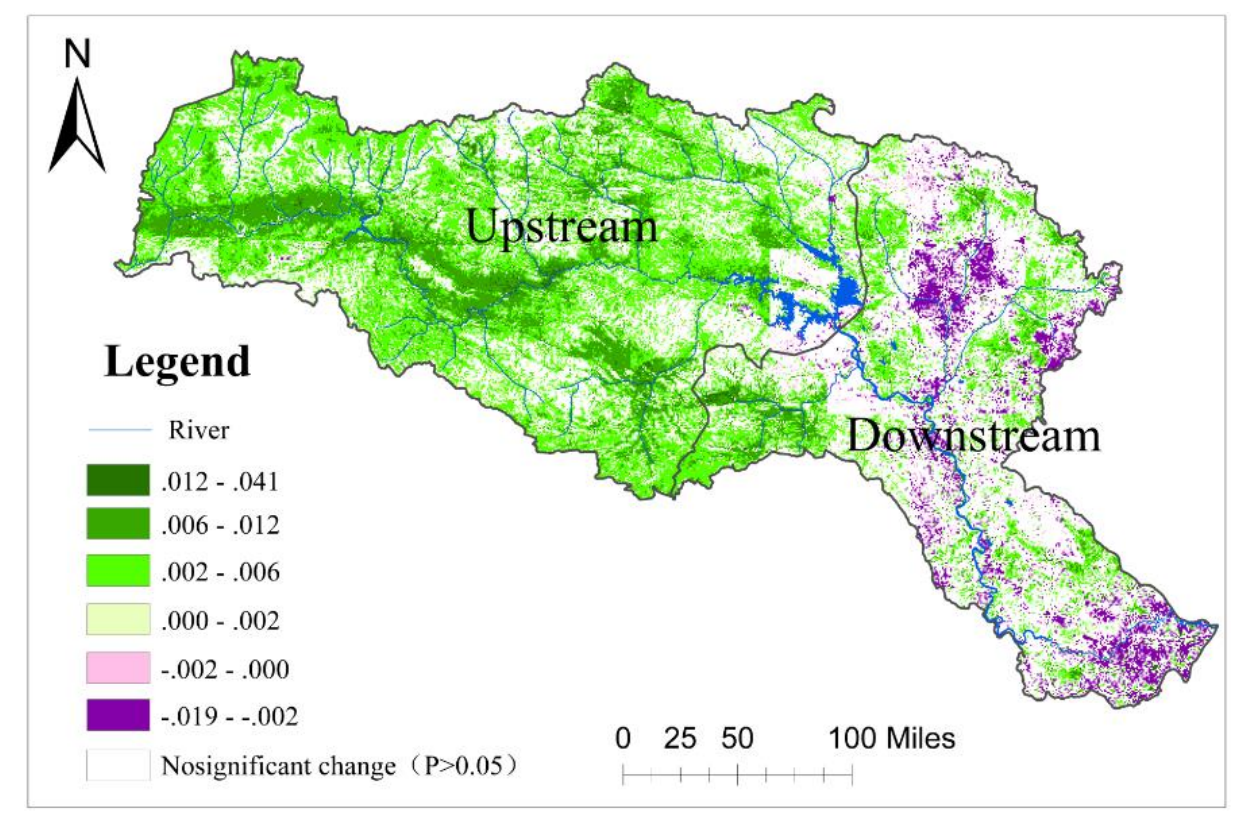

Figure. 4 NDVI change trend and significance test results from 1982 to 2018 (The map was created using ESRI ArcGIS 10.3, http://www.esri.com/sofware/arcgis/arcgis-for-desktop).

\section{Correlation between precipitation, temperature and NDVI}

Fig. 5 shows that the annual average temperature increased at a rate of $0.37{ }^{\circ} \mathrm{C}$ year- 1 
from 1982 to 2018, the highest annual average temperature appeared in 2013, at a

299 value of $15.19^{\circ} \mathrm{C}$, and the lowest temperature was observed in 1984 , at a value of

$30013.14{ }^{\circ} \mathrm{C}$. The annual precipitation increased at a rate of $12.098 \mathrm{~mm}$ year-1 from 1982

to 2018 , the highest annual precipitation occurred in 1983 , at a value of $1229.43 \mathrm{~mm}$, and the lowest value appeared in 1997, at a value of $618.88 \mathrm{~mm}$.

The annual precipitation and annual mean temperature values were spatially heterogeneous (Fig. 6). The annual average temperature decreases gradually from south to north, the highest annual average temperature is located in the southeast, and the lowest is located in the west and north. The annual precipitation also shows a southeast and the southwest, and the lowest is located in the northern.

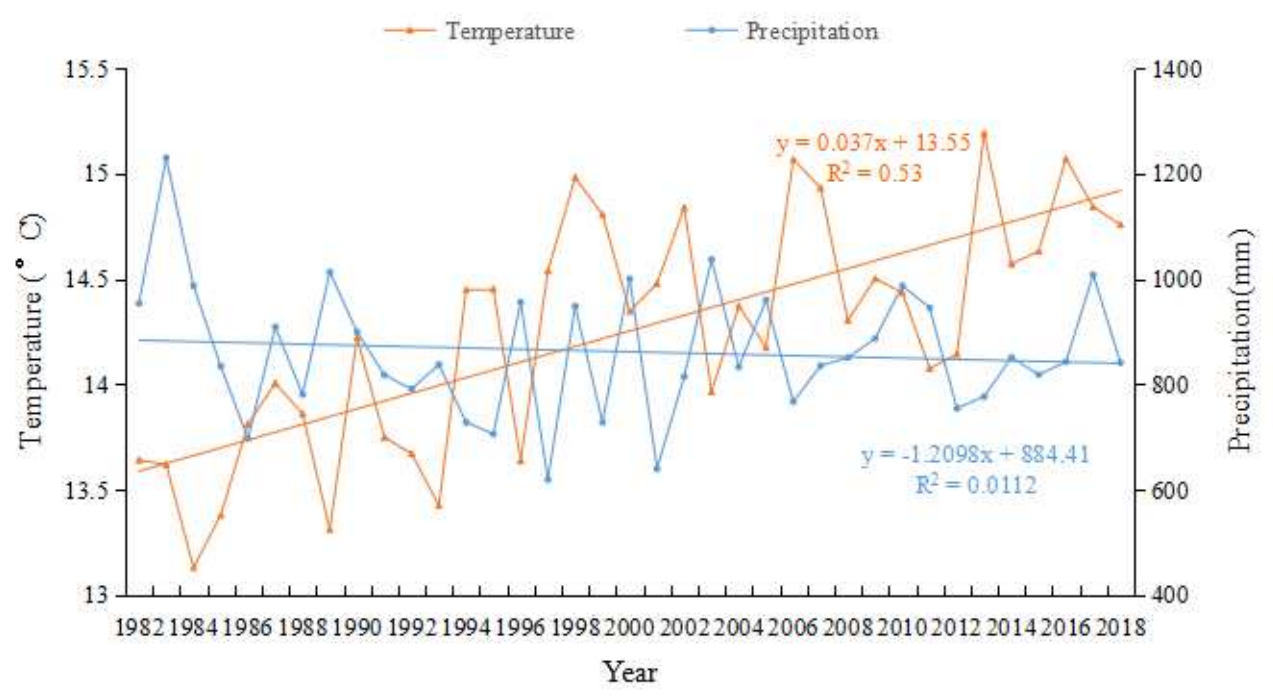

Figure. 5 Trends in the annual average temperature and precipitation from 1982 to 

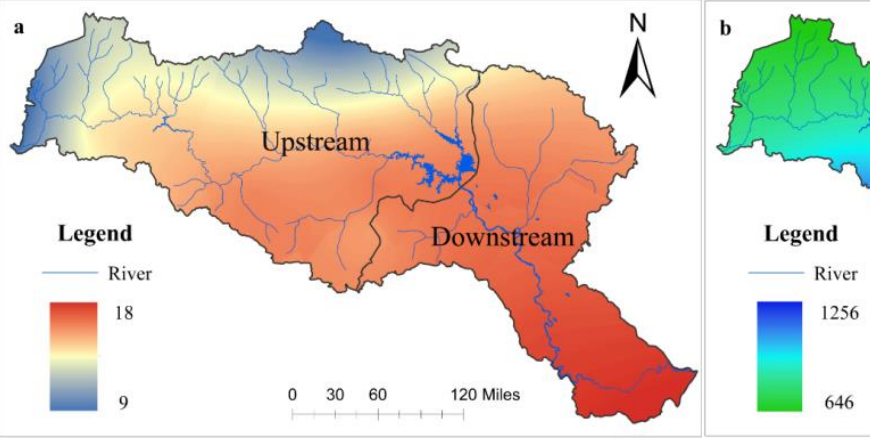

Figure. 6 a) Spatial distribution of the average temperature from 1982 to 2018 ; b)

Spatial distribution of the precipitation from 1982 to 2018 (The map was created using ESRI ArcGIS 10.3, http://www.esri.com/sofware/arcgis/arcgis-for-desktop). The correlation of annual NDVI, annual climate data and monthly NDVI and monthly climate data were analyzed. The results show that the annual NDVI has no significant positive correlation with annual temperature and precipitation, and the correlation coefficients are 0.125 and 0.320 , respectively. There was a significant positive correlation between monthly NDVI and monthly average temperature, with a correlation coefficient of $0.708(\mathrm{P}<0.05)$. There was no significant negative correlation between monthly NDVI and monthly average precipitation, with a correlation coefficient of 0.199 . Overall, the influence of temperature on NDVI is greater than that of precipitation.

Based on the pixel scale, partial correlation coefficients of monthly average temperature, monthly precipitation and monthly average NDVI were calculated and tested for significance (Fig. 7). The results show that $95.78 \%$ of the pixel temperature has a positive correlation with NDVI $(81.90 \%$ significantly with $\mathrm{p}<0.05)$, and $4.22 \%$ of the pixel temperature has a negative correlation with NDVI. On the spatial distribution, except in the South and East, the temperature in other regions showed a 
significant positive correlation with NDVI. A total of $27.28 \%$ of the pixel precipitation has a positive correlation with NDVI $(28.94 \%$ significantly with $\mathrm{p}<$ 0.05 ), and $72.72 \%$ of the pixel temperature has a negative correlation with NDVI (71.06\% significantly with $\mathrm{p}<0.05)$. On the spatial distribution, precipitation and NDVI are negatively correlated with the Hanzhong Basin and the north and positively correlated with parts of the southeast.
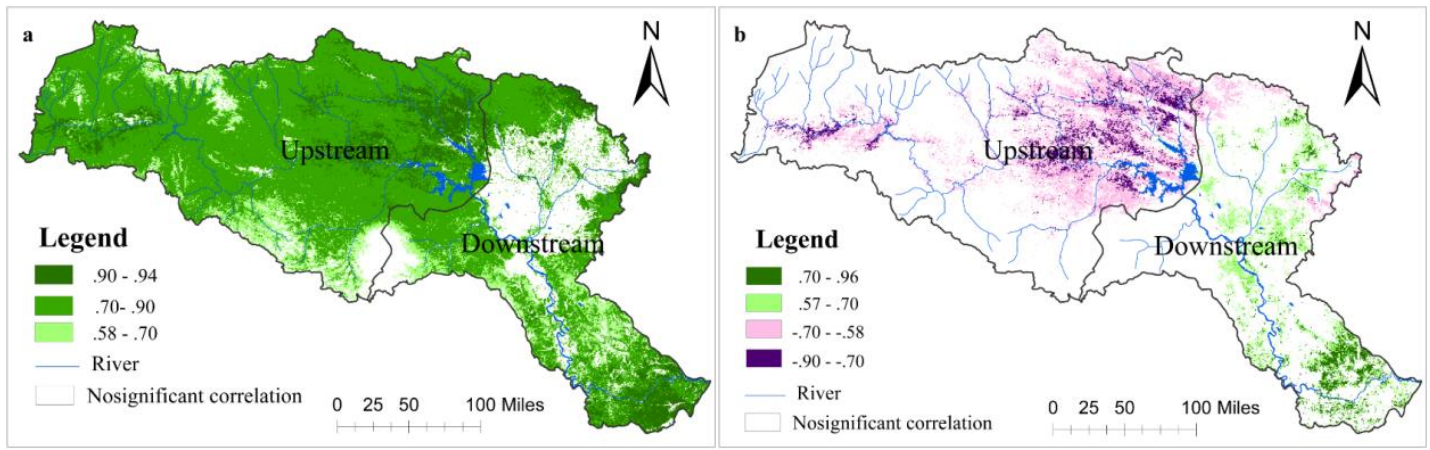

Figure 7 a) Spatial distribution and significance test of the partial correlation coefficient between temperature and NDVI; b) spatial distribution and significance test of the partial correlation coefficient between precipitation and NDVI (The map was created using ESRI ArcGIS 10.3, http://www.esri.com/sofware/arcgis/arcgis-fordesktop).

\section{Residual analysis and land use change}

Based on regression analysis of NDVI and precipitation and temperature, the residuals of the NDVI are calculated on the pixel scale (Fig. 8). Positive values indicate that other factors have a positive effect on regional NDVI changes, while negative values indicate an adverse effect. The results show that the area of the positive value of the residual value is greater than the area of the negative value. In terms of spatial distribution, positive values are mainly distributed upstream of the 

around the Jianghan Plain, Nanyang Basin, and central cities.

352

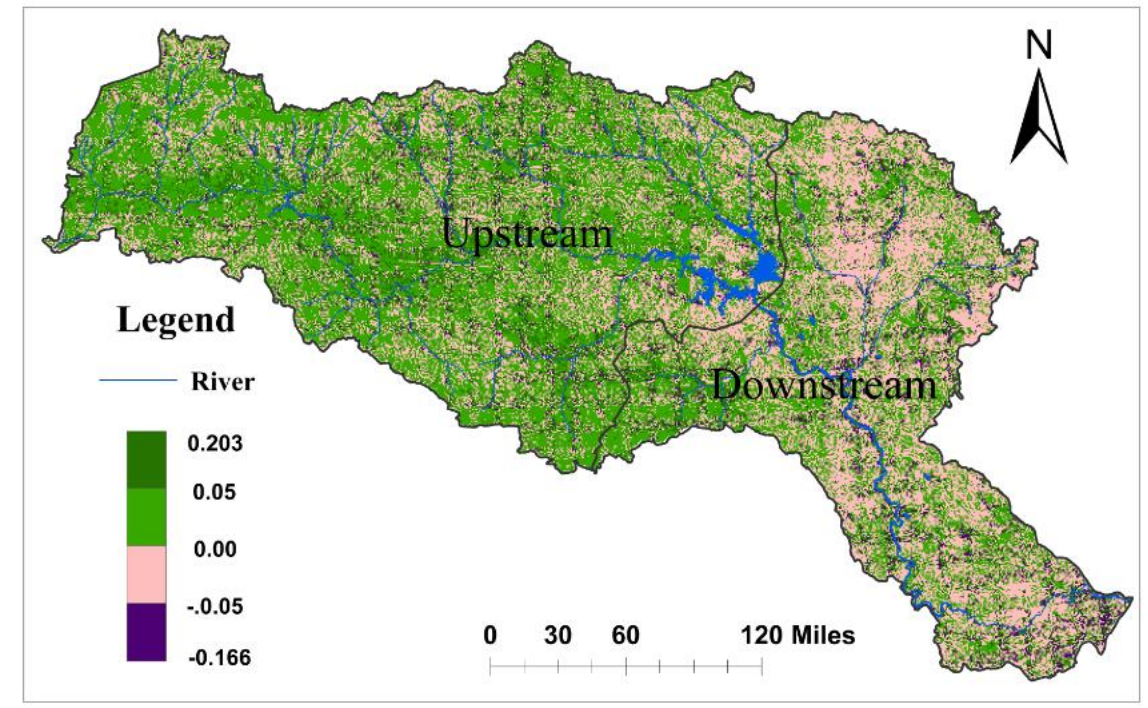

Figure. 8 Spatial distribution of the residual mean from 1982 to 2018 (The map was created using ESRI ArcGIS 10.3, http://www.esri.com/sofware/arcgis/arcgis-fordesktop).

Fig. 9 shows the spatial distribution of the comprehensive contribution of residual and climatic factors to NDVI changes. The results show that the comprehensive contributions of climate and human activity factors to NDVI changes were $92.03 \%$ and $7.97 \%$, respectively, the comprehensive contribution of climate factors to NDVI changes is much greater than the residual contribution, which is the dominant factor in NDVI changes. However, the comprehensive contributions of the two factors exhibit notable spatial heterogeneity. The comprehensive contribution of residuals is higher only on both sides of the river upstream of the dam and around the central city downstream of the dam and lower in other areas. In regions with high residual comprehensive contribution, the influence of climate factors is small, and other 
367 factors.

368

Figure. 9 a) Spatial distribution of the average comprehensive contribution of residual from 1982 to 2018; b) Spatial distribution of the average comprehensive contribution of climate factors from 1982 to 2018. (The map was created using ESRI ArcGIS 10.3, http://www.esri.com/sofware/arcgis/arcgis-for-desktop).

The least squares method was used to fit the spatial variation in the comprehensive contributions of residual and climate factors from 1982 to 2018 (Fig. 10). The results showed that the change rate of the comprehensive contribution of residuals was 0.124 year $^{-1}$, the change rate of the comprehensive contribution of natural factors was -0.183 year $^{-1}$, and the contribution rate of residuals showed an upward trend, while the natural factors showed a downward trend. Spatially, in areas with high residual contributions on both sides of the river upstream of the dam and around the central city downstream of the dam, the comprehensive contribution of residuals showed a significant upward trend, while the comprehensive contribution of natural factors showed a significant downward trend. In other areas, the comprehensive contribution of residuals also shows an increasing trend, but the 
degree of change is smaller.

385

391
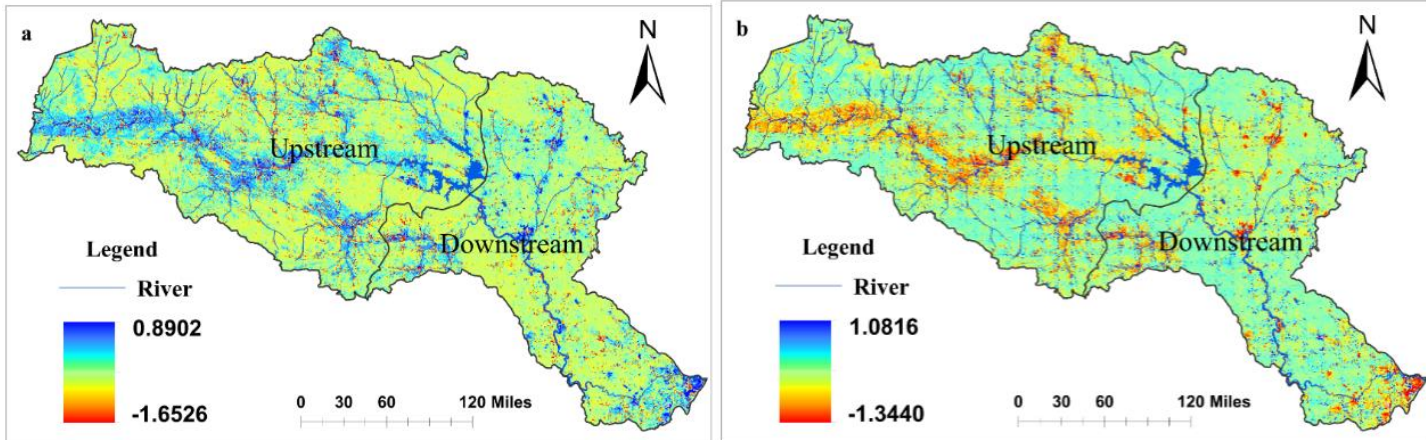

Figure. 10 a) Spatial variation trend of the comprehensive contribution degree of residual from 1982 to 2018; b) Spatial variation trend of the comprehensive contribution degree of climate factors from 1982 to 2018 (The map was created using ESRI ArcGIS 10.3, http://www.esri.com/sofware/arcgis/arcgis-for-desktop). Table 1 Land use change transfer matrix of the Hanjiang River basin in 1980-2018

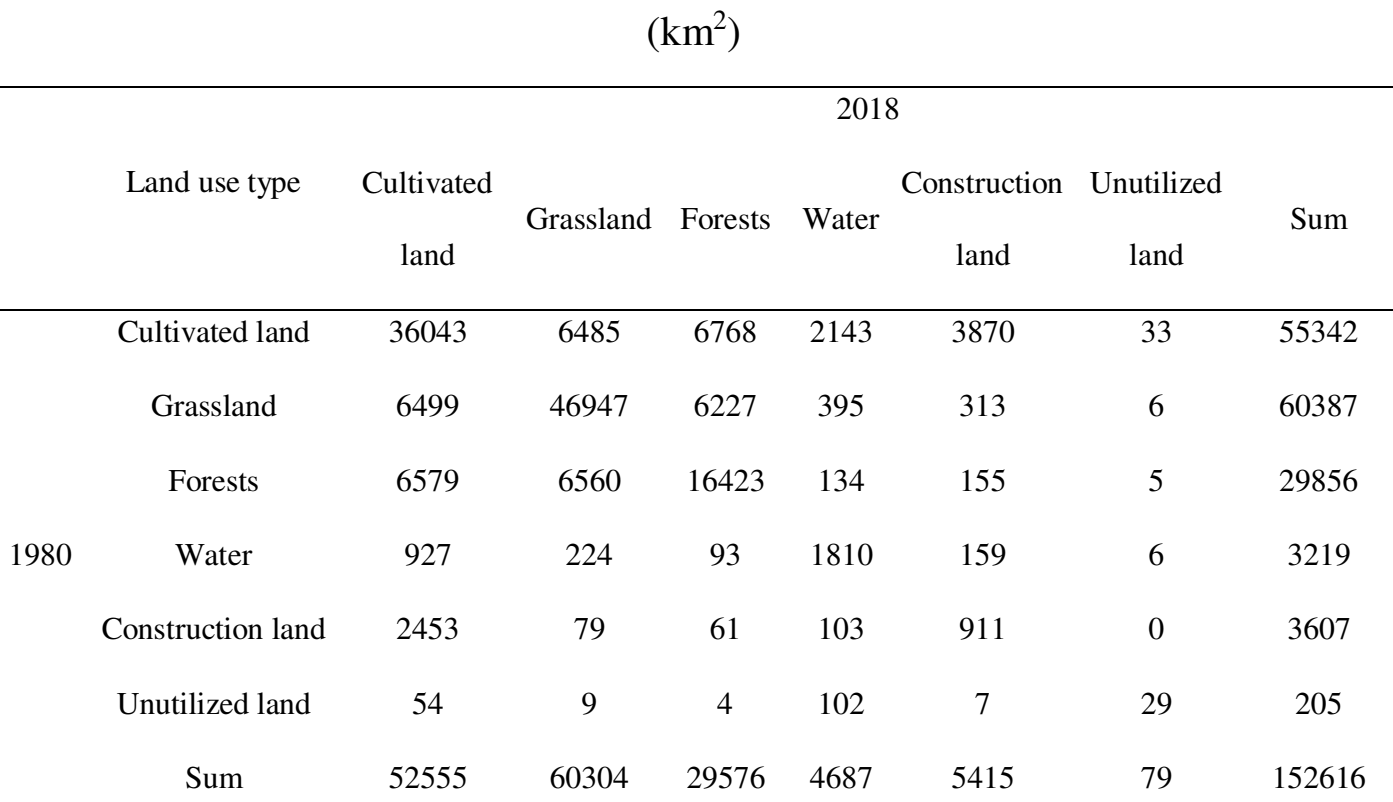

Table 1 shows the land use change from 1980 to 2018. The results show that the overall land use change over 39 years is as follows: cultivated land, grassland, and forests decreased, while water, cultivated land, and unutilized land increased. The 
cultivated land, grassland and forests decreased by $2787 \mathrm{~km}^{2}, 280 \mathrm{~km}^{2}$ and $83 \mathrm{~km}^{2}$, respectively, while water, cultivated land and unutilized land increased by $1468 \mathrm{~km}^{2}$, $1808 \mathrm{~km}^{2}$ and $126 \mathrm{~km}^{2}$, respectively. Therefore, the land types with the largest change are cultivated land, water and construction land; the reduced cultivated land is mainly converted into water and construction land; the increased water is mainly converted from cultivated land and forests; and the increased construction land is mainly converted from cultivated land and forests.

Fig. 11a shows the area of the increase in the six types of land use in 2018. It can be seen from the figure that the upstream area of the dam is mainly increased by cultivated land, forests and grassland, and the increased area is located in the west and north of the upstream area of the dam. The downstream area of the dam is mainly represented by the increase in water and construction land. The location of the increase in water is located in the south downstream of the dam, and the location of the increase in construction land is around the central city.

Since the area changes of cultivated land, forestland and grassland are transformed from each other, we analyze their conversion in Fig. 11b. On both sides of the river upstream of the dam, mainly transformed from cultivated land to forestland and grassland; in the south and downstream of the dam, mainly transformed from forestland to cultivated land. 

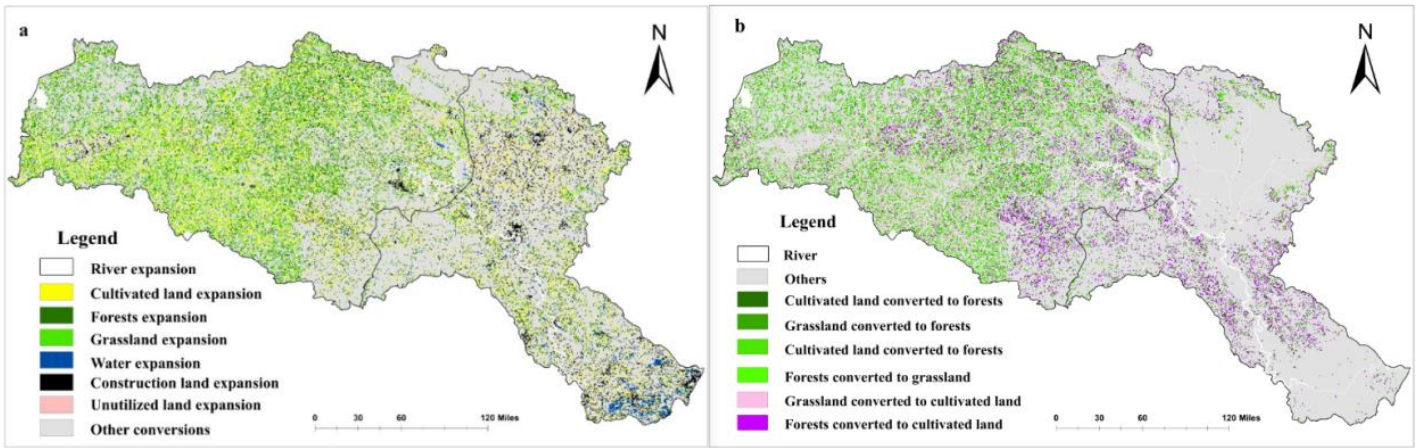

Figure. 11 a) Expanded area of different land use types from 1980 to 2018; b)

Conversion of cultivated land, forests and grassland from 1980 to 2018 (The map was created using ESRI ArcGIS 10.3, http://www.esri.com/sofware/arcgis/arcgis-fordesktop).

In summary, from 1980 to 2018 , the changes in land use types are consistent with tresidual results. We believe that human activity factors account for a large proportion of residual values, and residual value is taken as a human activity factor to participate in the discussion.

\section{Analysis}

\section{NDVI spatiotemporal change}

From 1982 to 2018, the NDVI values in the upper and lower reaches of the Danjiangkou Dam showed an overall upward trend, reflecting the improvement in regional vegetation. The Danjiangkou Reservoir is the core water source of the Southto-North Water Transfer Project. With the development of the Middle Route of the South-to-North Water Transfer Project and popularization of the concept of ecological civilization, state and local governments realize that the ecological environment of the water source area determines the water quality and quantity of the water diversion project. These requirements will affect the success or failure of water 
diversion projects and influence the reproductive health and life of the people in the water-receiving areas. Relevant departments have implemented a series of ecological measures, including natural forest protection projects, conversion of farmland to forestry projects, a number of water conservancy compensation projects ${ }^{47}$, and active promotion of the downstream cascade development and modernization pilot construction of the dam ${ }^{48}$. The implementation of these projects has promoted the increase in NDVI in the upstream and downstream vegetation of the dam to a certain extent. The natural forest protection project started in 1998, and the policy of returning farmland to forestry began in 1999. As the first pilot project, the implementation of ecological protection in Shaanxi Province in the upper reaches of the basin has gradually stabilized the regional vegetation area. This phenomenon may be the reason that the NDVI fluctuated greatly before 2001, and the trend of change was more stable after 2001.

The average NDVI in the upstream region of the dam is higher than that in the downstream region, and the NDVI in the upstream region mainly increases significantly during the study period, while the NDVI in the downstream region is mainly degraded. The upstream region of the dam is located in Shanxi Province, and its vegetation cover is mainly forestland, while the downstream region hosts many central cities, so the vegetation cover in the upstream region is better than that in the downstream region. At the same time, the upstream region of the basin is the key area of ecological protection work, and the implementation of various ecological engineering works has improved the NDVI as a whole, while the downstream area is 
dominated by cultivated land and cities. Economic development and urban expansion

457 will affect regional vegetation growth.

458

459

460

461

462

463

464

465

466

467

468

469

470

471

472

473

474

475

476

477

\section{Analysis of the influencing factors}

Between 1982 and 2018, the precipitation showed a decreasing trend, while the temperature showed an increasing trend, indicating that the regional climate gradually became warmer and drier. There is a significant positive correlation between regional temperature and NDVI and a negative correlation between precipitation and NDVI. Therefore, the climate change trend is conducive to the growth of regional vegetation. The overall growth trend of vegetation in the study period is closely related to the climate change trend.

The study area has a developed water system, rich water resources, relatively small dependence of vegetation on precipitation, and sufficient heat resources will promote the growth of vegetation; therefore, temperature has a greater effect on NDVI than precipitation. In the north upstream of the dam and Jianghan Plain downstream, precipitation and temperature have a significant correlation with NDVI. The northern part is located in a low-lying valley area, and near the Danjiangkou Reservoir, the water system is developed. Excessive precipitation will increase soil moisture, resulting in large surface latent heat evaporation, lowering the temperature and affecting the photosynthesis of plants, but sufficient heat resources will promote the growth of valley vegetation. The Jianghan Plain is a plain agricultural area, and sufficient water and heat resources will promote the growth of regional crops. In the Nanyang Basin, the impact of precipitation and temperature on NDVI is not 
significant. The land use in this area is mainly cultivated land, the economic

479 development is good, and it is greatly affected by human factors. Vegetation changes 480 are not fully synchronized with climate changes. Except for the Nanyang Basin, the 481 temperature has no significant effect on vegetation in high-altitude areas. At higher 482 altitudes, water and heat resources are distributed less, and vegetation growth is less 483 dependent on climatic factors.

In the analysis of residual values, human activities in the upper reaches of the river basin have a positive impact on NDVI, while human activities in the lower basin have a negative impact. Combined with land use changes, upstream of the dam, the changes in land use types are mainly the conversion of cultivated land to forestland land and grassland. These changes are affected by the implementation of water and soil conservation projects and the implementation of returning farmland to forest. Relevant research shows that ${ }^{49}$, as of 2009 , the afforestation of returned farmland has been completed $21.88 \times 10^{4} \mathrm{hm}^{2}$, the implementation of these policies has promoted vegetation growth upstream of the $\mathrm{dam}^{50}$. The main change downstream of the dam is the conversion of cultivated land to construction land, forestland to cultivated land. The main change downstream of the dam is the conversion of cultivated land to channels, serious soil erosion, and a significant downward trend in vegetation coverage. At the same time, the unreasonable use of land by humans in the plain basin 
area has exacerbated soil erosion, resulting in bare surface and worsening vegetation coverage. Therefore, the downstream human activities are mainly represented by the expansion of downstream cities, the phenomenon of construction land occupying cultivated land and forestland, and unreasonable agricultural cultivation.

In summary, climatic factors are the main factors affecting the vegetation changes in the upper and lower reaches of the Danjiangkou Dam, but human activities have gradually become an important factor affecting regional vegetation changes, and the degree of influence has gradually increased.

\section{Discussion}

Climate change is a long-term process, and the length of meteorological and hydrological data used for analysis to a large extent determines the trend results. At the same time, the length of time series is also an important issue to analyze the impact of human activities ${ }^{51}$, urban development, land use change, and the benefit of ecological protection measures are all long-term processes, and it is difficult to capture the changes in short-term monitoring ${ }^{52}$. In this study, we used the EOT algorithm to build long-sequence $1 \mathrm{~km}$ resolution NDVI data based on GIMMS NDVI and MODIS NDVI. Since the resolution of GIMMS NDVI is $8 \mathrm{~km}$ and the resolution of MODIS NDVI is $250 \mathrm{~m}$, there may be a problem of mixed pixels when fitting the EOT algorithm, which may have a certain impact on the results. However, the land use types upstream of the dam are mainly forestland and grassland and are continuously distributed; the downstream of the dam is mainly cultivated land and construction land, with a relatively concentrated distribution, and the mixed pixels 
522 have relatively little influence on the prediction of the EOT algorithm. Based on the 523 calculated error coefficients, the prediction performance of the EOT algorithm is 524 good.

By analyzing the NDVI time series, we conclude that the vegetation restoration

effect in the study area from 1982 to 2018 is better, which is closely related to climate

change, especially temperature. Climate warming not only extends the vegetation growth cycle but also accelerates the decomposition of soil organic matter and the release of nutrients, which is beneficial to the accelerated growth of vegetation ${ }^{53}$. This result is consistent with the research results of $\mathrm{Liu}^{54}$ and $\mathrm{Li}^{55}$ in this region. In this study, human activities such as returning farmland to forest upstream of the dam are important factors affecting vegetation restoration. This result has been verified by some scholars' sub studies. Jin et al. ${ }^{56}$ found that human activities such as returning farmland to forest have a great impact on vegetation restoration in Shaanxi Province, and their contribution rates to vegetation increase are more than $65 \%$. Zhang et al. ${ }^{57}$ found that human activities affect vegetation changes by changing land use types and have a positive impact on vegetation upstream of the dam. Piao et al. ${ }^{58}$ considered that greening engineering plays an important role in vegetation restoration. At the same time, human activities will also have a negative impact on vegetation growth, which is mainly manifested in the encroachment of farmland and forests by urban development downstream of the dam. This is consistent with the results of Zhang et al. ${ }^{57}$ The research by Jin et al. ${ }^{59}$ also showed that the negative impact of human activities on vegetation changes is more pronounced in metropolitan agglomeration areas. 
544 Compared with other scholars' research on the Danjiangkou Dam, this manuscript 545 constructed a long-time high spatial resolution NDVI data set, quantitatively analyzed 546 the relative contributions of climate and human activities to vegetation changes, and 547 based on the types of land use, the expression of human activities in the upstream and 548 downstream of the dam is discussed, which provides a theoretical basis for the 549 formulation of regional ecological protection measures. However, some deficiencies 550 remained in this study. For example, the term "human activity" in this study only 551 considered the change of land use type, whereas the total content of human activity is 552 very rich (e.g., vegetation construction, agricultural technology progress and urban expansion). On the other hand, when the residual method is used to separate the influence of human activities on NDVI changes, it only establishes the multiple regression equation between climatic factors and NDVI and only considers the influence of natural factors such as topography, which may have some impact on the results. In future research, we will consider a variety of factors, build an evaluation system of human activities, and conduct an in-depth analysis of the impact of human activities on regional vegetation.

\section{Conclusion}

Based on GIMMS NDVI and MODIS NDVI data sets, the EOT algorithm is used to construct $1 \mathrm{~km}$ resolution NDVI data sets from 1982 to 2018. Based on the temperature and precipitation data, the driving factors of NDVI change upstream and downstream of the Danjiangkou dam and their corresponding contributions are analyzed using change trend analysis and residual analysis methods. The main 
conclusions are as follows:

567 (1) From 1982 to 2018, the overall NDVI of the Danjiangkou water source area 568 showed a significant increasing trend, with a change trend of 0.017 year $^{-1}(\mathrm{P}<0.05)$, 569 but showed obvious spatial heterogeneity. The significant increase area is located near 570 the valley upstream of the dam, while the significantly decreased area is mainly 571 distributed in the basin downstream of the dam and around the central city.

572 (2) The influence of temperature on NDVI is greater than that of precipitation, which 573 is the main climatic factor affecting NDVI change. The influence of temperature and 574 precipitation on NDVI shows obvious spatial heterogeneity. In the upstream valley 575 area and downstream farming area, the correlation among NDVI, precipitation and 576 temperature is significant; in the basin area with higher terrain in the upstream and 577 downstream, the correlation among NDVI, precipitation and temperature is not 578 significant.

579 (3) Human activities have a positive impact on the NDVI in the study area, but the human activities upstream and downstream of the dam are different in performance and have different effects on the NDVI. Human activities have a positive impact on the NDVI upstream of the dam, which is mainly reflected in ecological measures such as returning farmland to forests. It has a negative impact on the NDVI downstream of the dam, which is mainly reflected in urban expansion and the occupation of

585 cultivated land and forestland by construction land.

(4) The climate factor is the leading factor in the change in NDVI. The comprehensive contribution of climate and human activities to the change in NDVI 
has great spatial heterogeneity. The comprehensive contribution of human activities around the upper river valleys and the lower central cities is greater. The comprehensive contribution of climate in other regions is much higher than that of human activities. The comprehensive contribution of human activities has shown an increasing trend in recent years and has become an important factor affecting NDVI.

Data availability: The data used in current study are available from the corresponding author upon reasonable request.

Author Contributions: The authors undertook different tasks for this paper. Hai Liu designed the research and revised the paper. Hongmeng Yuan wrote the paper. Yuan Zhang analyzed the data. Liang Zheng provided direction to the research work. All authors have read and approved the final manuscript.

Funding: This research was financially supported by National Key Research and Development Program of China (2018YFC1506500), National Natural Science Foundation of China (41971402).

Conflicts of Interest: The authors declare no conflict of interest. The funders had no role in the design of the study; in the collection, analyses, or interpretation of data; in the writing of the manuscript, or in the decision to publish the results.

Acknowledgments: We are grateful to the MODIS、GIMMS and CMDC team for making the data freely available. The authors would like to thank the anonymous reviewers for their very constructive remarks.

\section{References:}

1. Lang, C. Do weather fluctuations cause people to seek information about climate change. Clim. Chang 125, 291-303 (2014). doi:10.1007/s10584-014-1180-6

2. Piao, S. et al. Interannual variations of monthly and seasonal normalized difference vegetation index ( NDVI ) in China from 1982 to 1999. J Geophys Res-atmos 108, 1-13 (2003). 
3. Piao, S., Fang, J. \& He, J. Variations in vegetation net primary production in the qinghaixizang plateau, china, from 1982 to 1999. Clim. Chang 74, 253-267 (2006). doi:10.1007/s10584-005-6339-8

4、 $\mathrm{Hu}, \mathrm{C} ., \mathrm{Fu}, \mathrm{B} ., \mathrm{Liu}, \mathrm{G} ., \mathrm{Jin}, \mathrm{T}$. \& Guo, L. Vegetation patterns influence on soil microbial biomass and functional diversity in a hilly area of the Loess Plateau, China. J Soil Sediment 10, 1082-1091 (2010)

5. Matteucci, S. D., Totino, M. \& Arístide, P. Ecological and social consequences of the Forest Transition Theory as applied to the Argentinean Great Chaco. Land Use Pol 51, 8 17 (2016).

6. Hansen, M. C. et al. High-resolution global maps of 21st-century forest cover change. Science 134, 850-854 (2013)

7. Liu, T. \& Yang, X. Remote Sensing of Environment Mapping vegetation in an urban area with strati fi ed classi fi cation and multiple endmember spectral mixture analysis. Remote Sens. Environ. 133, 251-264 (2013).

8. Hansen, M. C., Stehman, S. V \& Potapov, P. V. Quantifification of global gross forest cover loss. Proc. Natl. Acad. Sci. USA 107, 8650-8655 (2010).

9. Liu, Y., Li, Y., Li, S. \& Motesharrei, S. Spatial and Temporal Patterns of Global NDVI Trends: Correlations with Climate and Human Factors. Remote Sens 7, 13233-13250 (2015). doi:10.3390/rs71013233

10. Pettorelli, N. et al. Using the satellite-derived NDVI to assess ecological responses to environmental change. Trends Ecol. Evol. 20, 503-510 (2005).

11. Tucker, C. J. Red and photographic infrared linear combinations for monitoring vegetation. Remote Sens. Environ. 150, 127-150 (1979).

12. Myneni, R. B., Hall, F. G., Sellers, P. J. \& Marshak, A. L. The Interpretation of Spectral Vegetation Indexes. IEEE Trans. Geosci. Remote Sensing 33, 481-486 (1995).

13. Lucht, W. et al. Climatic Control of the High-Latitude Vegetation Greening Trend and Pinatubo Effect. Science 296, 8-11 (1995).

14. Zhang, Y. et al. Agricultural and Forest Meteorology Seasonal and interannual changes in vegetation activity of tropical forests in Southeast Asia. Agric. For. Meteorol. 224, 1-10 
15. Nemani, R. R. et al. Climate-driven increases in global terrestrial net primary production from 1982 to 1999. Science 300, 1560-1563 (2003).

16. Park, H. et al. Remote Sensing of Environment Nonlinear response of vegetation green-up to local temperature variations in temperate and boreal forests in the Northern Hemisphere. Remote Sens. Environ. 165, 100-108 (2015).

17. Pearson, R. G. et al. Shifts in Arctic vegetation and associated feedbacks under climate change. Nat. Clim. Chang. 3, 673-677 (2013).

18. Gottfried, M. et al. Continent-wide response of mountain vegetation to climate change. Nat. Clim. Chang. 2, 111-115 (2012).

19. Li, S., Wang, Z., Lai, C. \& Lin, G. Quantitative assessment of the relative impacts of climate change and human activity on fl ood susceptibility based on a cloud model. $J$. Hydrol. 588, 125051 (2020).

20. Feng, Q., Ma, H., Jiang, X., Wang, X. \& Cao, S. What Has Caused Desertification in China ? Nat. Publ. Gr. 1-8 (2012). doi:10.1038/srep15998

21. Feng, L. et al. Remote Sensing of Environment Assessment of inundation changes of Poyang Lake using MODIS observations between 2000 and 2010. Remote Sens. Environ. 121, 80-92 (2012).

22. Wang, C., Gao, Q., Wang, X. \& Yu, M. Spatially differentiated trends in urbanization, agricultural land abandonment and reclamation, and woodland recovery in Northern China. Nat. Publ. Gr. 1-12 (2016). doi:10.1038/srep37658

23. Zhao, A., Zhang, A., Liu, X. \& Cao, S. Spatiotemporal changes of normalized difference vegetation index ( NDVI) and response to climate extremes and ecological restoration in the Loess Plateau, China. Theor. Appl. Climatol. 132, 555-567 (2017). doi:10.1007/s00704-017-2107-8

24. Jiang, M., Tian, S., Zheng, Z., Zhan, Q. \& He, Y. Human Activity Influences on Vegetation Cover Changes in Beijing, China, from 2000 to 2015. Remote Sens 9, 1-19 (2015). doi:10.3390/rs9030271

25. Jin, K. Responses of Vegetation Cover to Environmental Change in Large Cities of China. 
26. Pan, Y. et al. A large and persistent carbon sink in the world's forests. Science 333, 98893. (2011)

27. Roger, A. \& Pielke, S. Land use and climate change. Science 310, 1625-1626. (2015). doi:10.1126/science. 1120529

28. Ma, Y. \& Fan, S. The temporal change of driving factors during the course of land desertification in arid region of North China : the case of Minqin County. Environ Geol 51, 999-1008 (2007). doi:10.1007/s00254-006-0369-Z

29. Xu, D., Li, C., Song, X. \& Ren, H. Catena The dynamics of deserti fi cation in the farming-pastoral region of North China over the past 10 years and their relationship to climate change and human activity. Catena 123, 11-22 (2014).

30. Song, Y., Jin, L. \& Wang, H. Vegetation Changes along the Qinghai-Tibet Plateau Engineering Corridor Since 2000 Induced by Climate Change and Human Activities. Remote Sens 10, 1-21 (2018). doi:10.3390/rs10010095

31. Li, L., Zhang, Y., Liu, L., Wu, J. \& Wang, Z. Spatiotemporal Patterns of Vegetation Greenness Change and Associated Climatic and Anthropogenic Drivers on the Tibetan Plateau during 2000 - 2015. Remote Sens 10, 1-16 (2015). doi:10.3390/rs10101525

32. Manh, Q., Bao, Q. \& Vlek, P. L. G. Hotspots of human-induced biomass productivity decline and their social - ecological types toward supporting national policy and local studies on combating land degradation. Glob. Planet. Change 121, 64-77 (2014).

33. Xu, D., Song, A., Li, D., Ding, X. \& Wang, Z. Assessing the relative role of climate change and human activities in deserti fi cation of North China from 1981 to 2010. Front. Earth Sci 13, 43-54 (2018).

34. Liu, H., Yin, J. \& Feng, L. The Dynamic Changes in the Storage of the Danjiangkou Reservoir and the Influence of the South-North Water Transfer Project. Sci. Rep. 1-12 (2018). doi:10.1038/s41598-018-26788-5

35. Zhao, J. et al. Long-term ( 2002 - 2017 ) impacts of Danjiangkou dam on thermal regimes of downstream Han River ( China ) using Landsat thermal infrared imagery. J. Hydrol. 589, 125135 (2020). 
36. Li, X., Ren, Z. \& Zhang, C. The correlation analysis and space-time changes of NDVI and hydro-thermal index in Hanjiang basin. Geogr Res 32, 1623-1633 (2013).

37. Hu, Y., Huang, J., Yu, X. \& Wang, C. Spatio-Temporal Trends of Vegetation Coverage and Their Causes in the Danjiangkou Reservoir Region During 2000 to 2015. Resources and Environment in the Yangtze Basin 27, 862-872. (2018)

38. Yang, Q., Meng, X., Huang,Q. \& Lin, M. Variation of Vegetation Index in upper reaches of Hanjiang River and its attribution Analysis. South-to-North Water Transfer and Water Science \& Technology. 1-16. (2019)

39. Rouse,J.W. \& Haas,D.W. Monitoring the Vernal Advancement and Retrogradation (Greenwave Effect) of Natural Vegetation. Greenbelt, Md:NASA Goddard Space Flight Cent 11-13. (1974)

40. Tucker, C. J. et al. An extended AVHRR 8-km NDVI dataset compatible with MODIS and SPOT vegetation NDVI data. Int. J. Remote Sens. 26, 4485-4498 (2005).

41. Beck, H. E. et al. Global evaluation of four AVHRR-NDVI data sets: Intercomparison and assessment against Landsat imagery. Remote Sens. Environ. 115, 2547-2563 (2011).

42. Li, H., Xie, Y. \& Mingguo, M. Reconstruction of temporal NDVI dataset: evaluation and case study. Remote Sens. Techology Appl. 24, 596-602 (2009).

43. Van Den Dool, H. M., Saha, S. \& Johansson, A. Empirical orthogonal teleconnections. $J$. Clim. 13, 1421-1435 (2000).

44. Appelhans, T., Detsch, F. \& Nauss, T. Remote: Empirical Orthogonal Teleconnections in R. R package version 0.3.0. http://CRAN.R-project.org/package=remote. (2016)

45. Appelhans, T. et al. Eco-meteorological characteristics of the southern slopes of Kilimanjaro, Tanzania. Int. J. Climatol. 36, 3245-3258 (2016).

46. Freund, R., Vail, R. \& Clunies-Ross, C. Residual analysis. J. Am. Stat. Assoc. 56, 98-104. (1961)

47. Du, Y., Wang, X. \& Cai, S. Effect and countermeasure of the middle route project of south to north water transfer on ecology and environment in the middle and lower reaches of Hanjiang River. Bulletin of the chinese academy of sciences $\mathbf{6 , 4 3 - 4 8 . ~ ( 2 0 0 5 ) ~}$

48. Xie, G., Lu, C. \& Leng, Y. Ecological assets valuation of the Tibetan Plateau. J. Nat. 
Resour 2, 189-196. (2003)

49. Wang, X., Li, Z. \& Li, P. Vegetation succession on retired croplands during their recovery processes in Dan-Han River Watershed of Shaanxi Province,Northwest China. Chin. J. Appl Ecol 23, 347-356. (2012)

50. Zhao, Y. \& Wei, F. Research of Converting Cropland to Forest and Grassland and Sustainable Development in Qingling-Bashan Mountains-An Example From Hanzhong City. Res. Soil Water Conserv. 13, 200-203. (2006)

51. Dey, P. \& Mishra, A. Separating the impacts of climate change and human activities on streamflow: A review of methodologies and critical assumptions. J. Hydrol. 548, 278-290 (2017).

52. Villarini, G., Serinaldi, F., Smith, J. A. \& Krajewski, W. F. On the stationarity of annual flood peaks in the continental United States during the 20th century. Water Resour. Res. 45, 1-17 (2009).

53. Li, J. et al. Changes of green-up day of vegetation growing season based on GIMMS $3 \mathrm{~g}$ NDVI in northern China in recent 30 years. Sci. Geogr. Sin. 37, 620-629. (2017).

54. Liu, H., Zheng, L. \& Yin, S. Multi-perspective analysis of vegetation cover changes and driving factors of long time series based on climate and terrain data in Hanjiang River Basin, China. Arab. J. Geosci. 11, (2018).

55. Li, X., Ren, Z. \& Zhang, C. The correlation analysis and space-time changes of NDVI and hydro-thermal index in Hanjiang basin. Geogra res. 32, 1623-1633. (2013).

56. Jin, K., Wang, F., Han, J., Shi, S. \& Ding, W. Contribution of climatic change and human activities to vegetation NDVI change over China during 1982-2015. Dili Xuebao/Acta Geogr. Sin. 75, 961-974 (2020).

57. Zhang, J. \& Ren, Z. Spatiotemporal pattern of net primary productivity in the Hanjiang River Basin. Acta Ecol. Sin. 36, 7667-7677. (2016)

58. Piao, S. et al. Detection and attribution of vegetation greening trend in China over the last 30 years. Glob. Chang. Biol. 21, 1601-1609 (2015).

59. Jin, K. Responses of Vegetation Cover to Environmental Change in Large Cities of China. Sustainability 10, 270. (2018). doi:10.3390/su10010270 


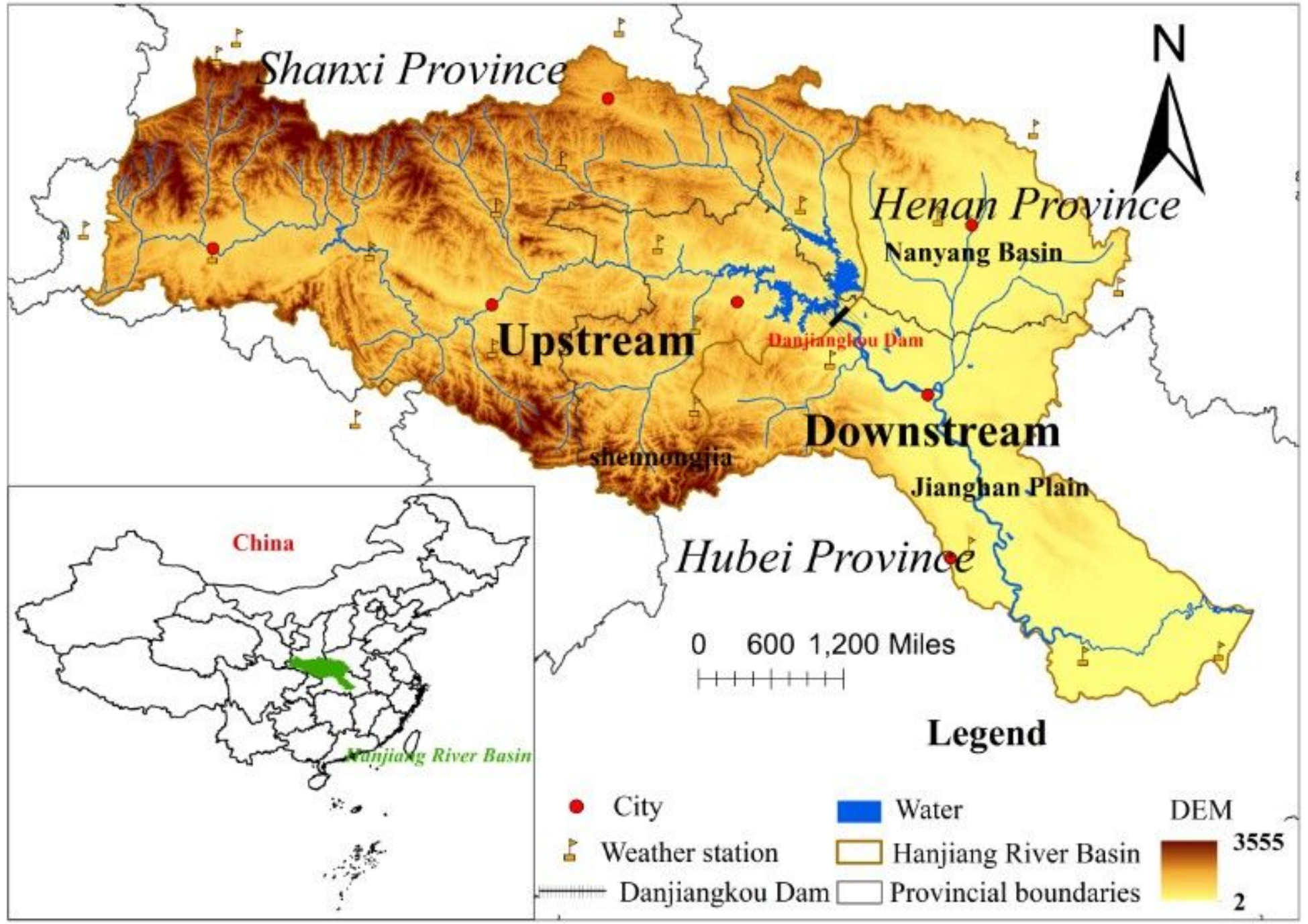

Figure 1

Location of the Danjiangkou Dam (The map was created using ESRI ArcGIS 10.3,

http://www.esri.com/sofware/arcgis/arcgis-for-desktop). Note: The designations employed and the presentation of the material on this map do not imply the expression of any opinion whatsoever on the part of Research Square concerning the legal status of any country, territory, city or area or of its authorities, or concerning the delimitation of its frontiers or boundaries. This map has been provided by the authors. 


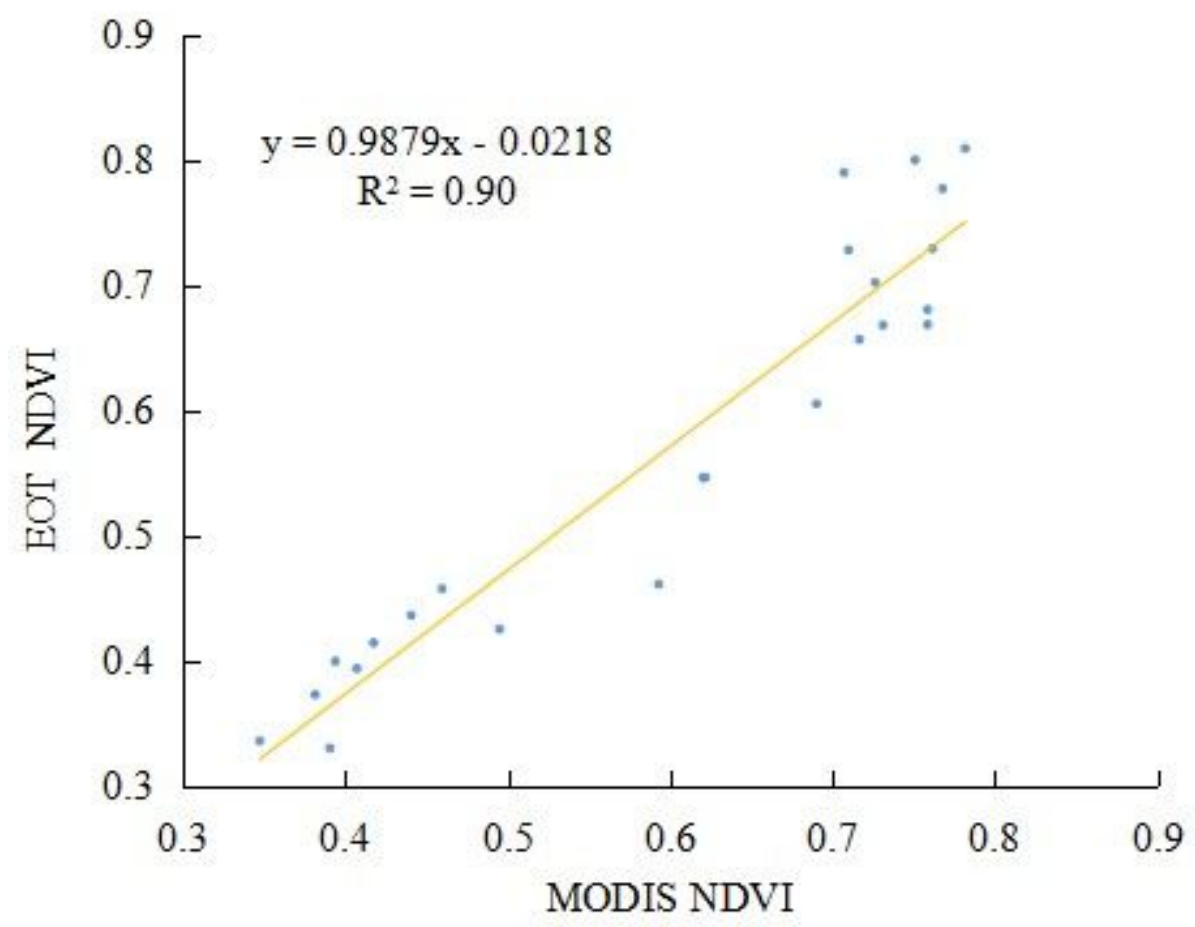

Figure 2

Verification of EOT NDVI and MODIS NDVI from 2005 to 2006

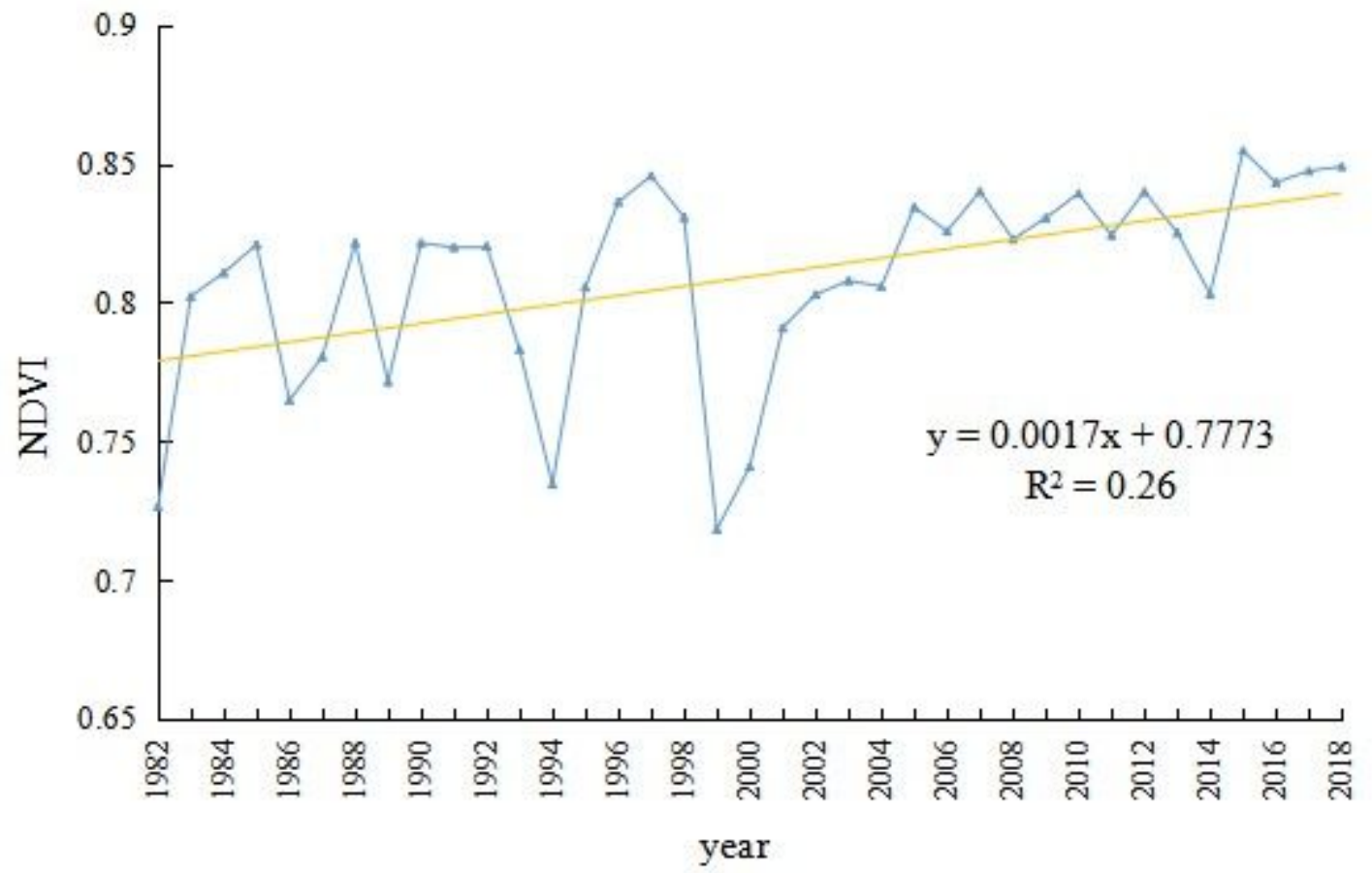

Figure 3

Annual average NDVI trends from 1982 to 2018 


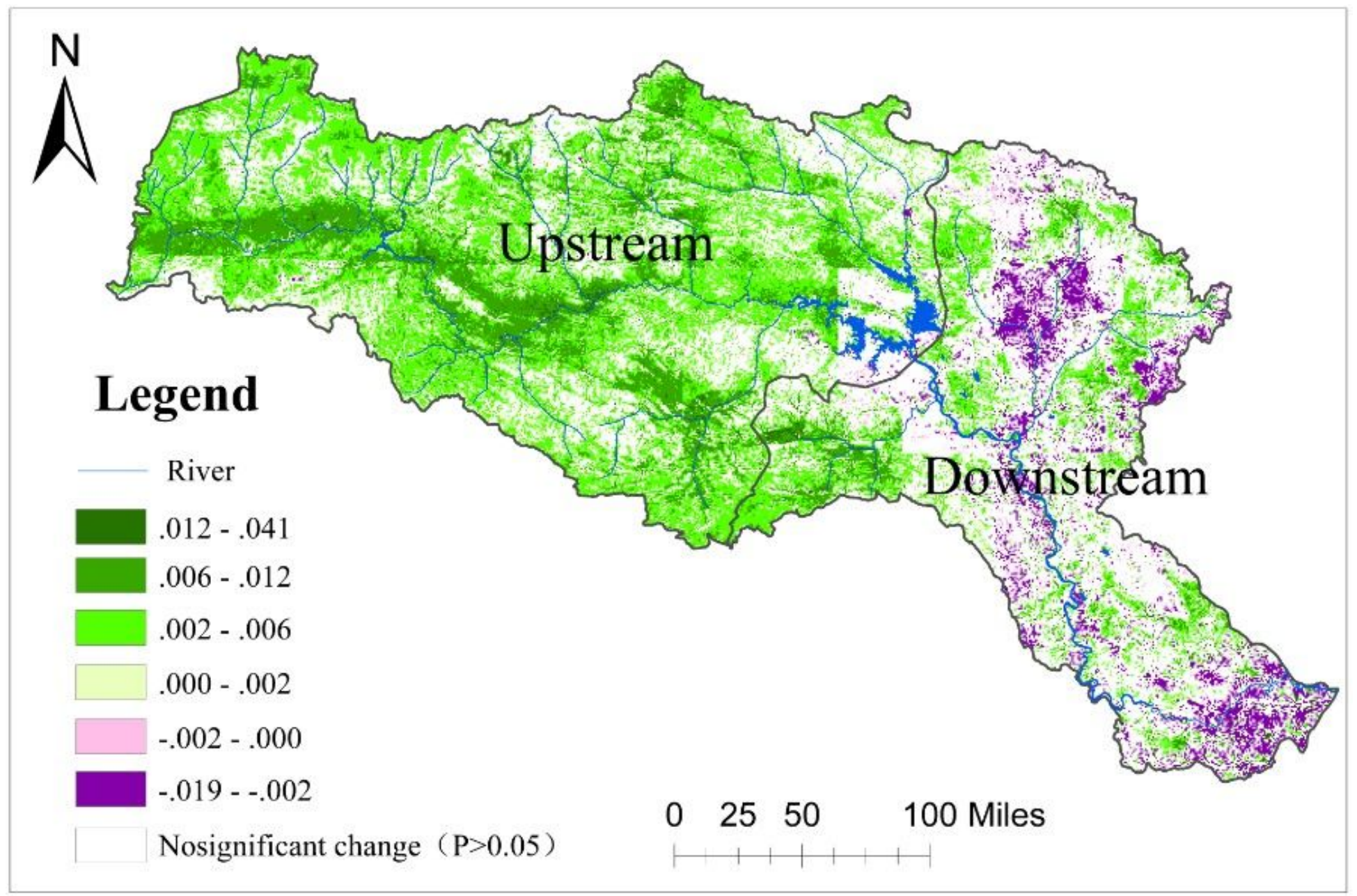

Figure 4

NDVI change trend and significance test results from 1982 to 2018 (The map was created using ESRI ArcGIS 10.3, http://www.esri.com/sofware/arcgis/arcgis-for-desktop). Note: The designations employed and the presentation of the material on this map do not imply the expression of any opinion whatsoever on the part of Research Square concerning the legal status of any country, territory, city or area or of its authorities, or concerning the delimitation of its frontiers or boundaries. This map has been provided by the authors. 


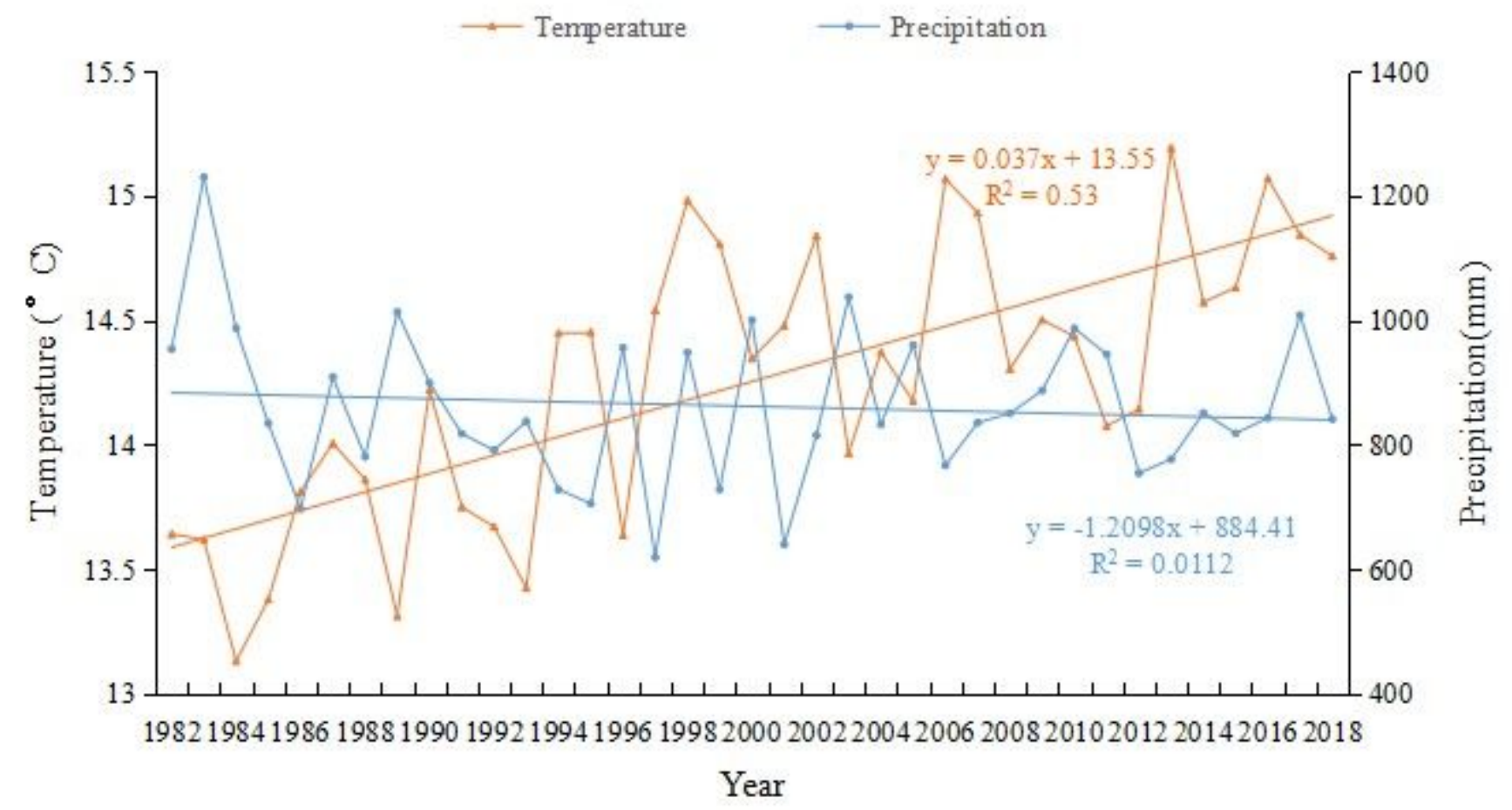

\section{Figure 5}

Trends in the annual average temperature and precipitation from 1982 to 2018

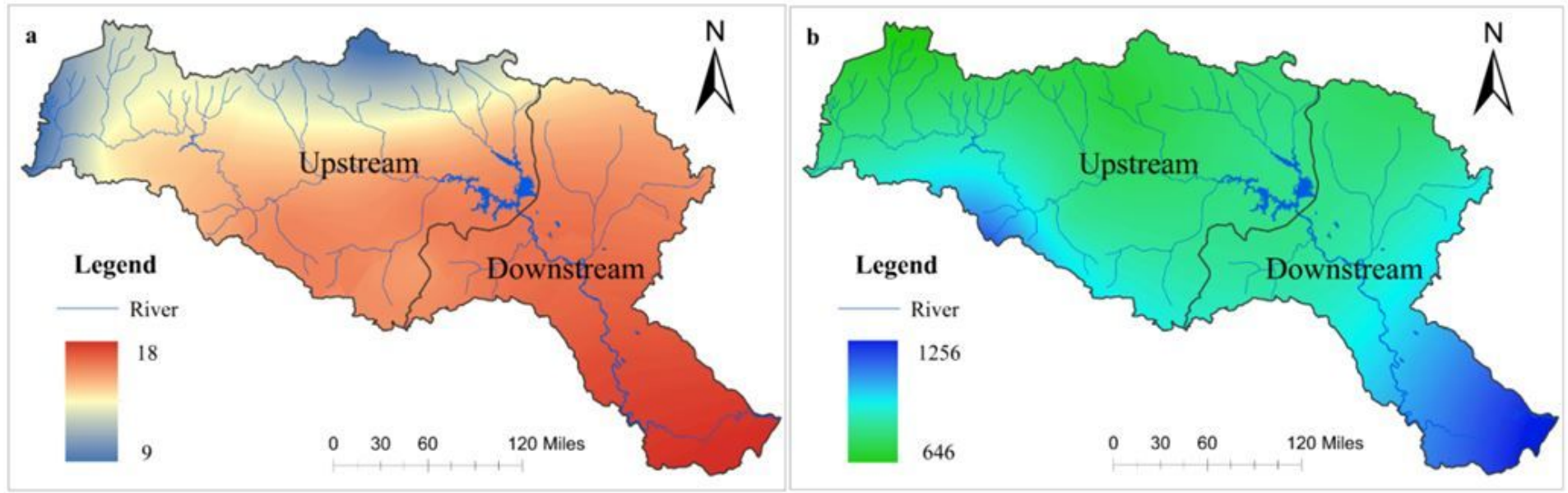

\section{Figure 6}

a) Spatial distribution of the average temperature from 1982 to 2018 ; b) Spatial distribution of the precipitation from 1982 to 2018 (The map was created using ESRI ArcGIS 10.3, http://www.esri.com/sofware/arcgis/arcgis-for-desktop). Note: The designations employed and the presentation of the material on this map do not imply the expression of any opinion whatsoever on the part of Research Square concerning the legal status of any country, territory, city or area or of its authorities, or concerning the delimitation of its frontiers or boundaries. This map has been provided by the authors. 


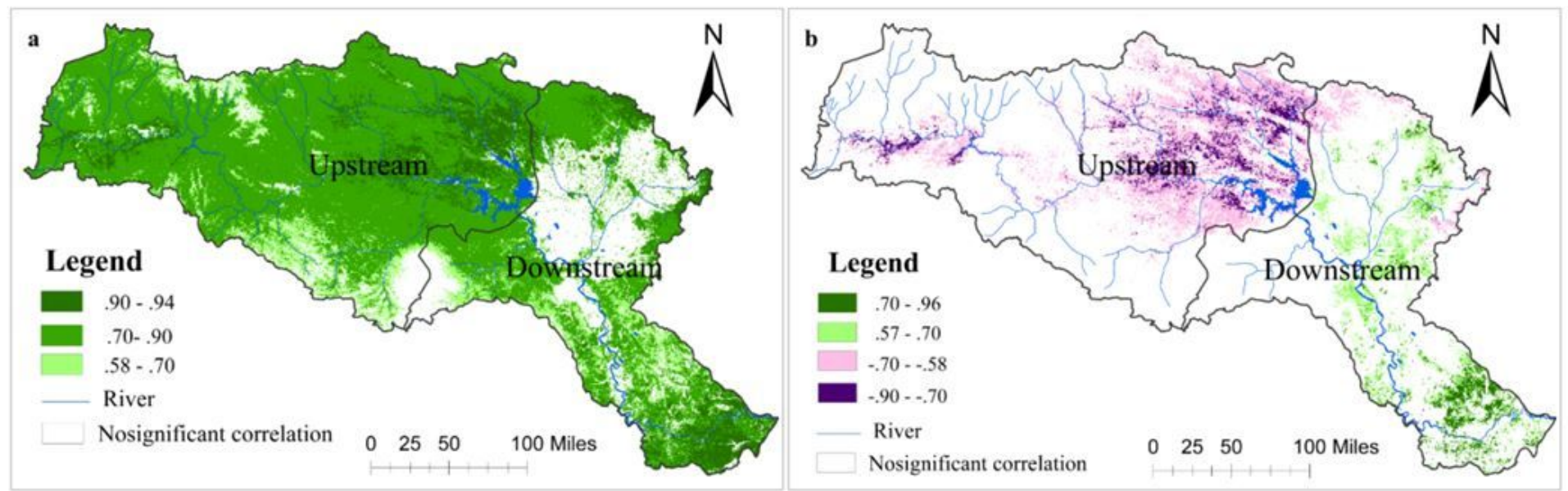

Figure 7

a) Spatial distribution and significance test of the partial correlation coefficient between temperature and $\mathrm{NDVl}$; b) spatial distribution and significance test of the partial correlation coefficient between precipitation and NDVI (The map was created using ESRI ArcGIS 10.3, http://www.esri.com/sofware/arcgis/arcgis-for-desktop). Note: The designations employed and the presentation of the material on this map do not imply the expression of any opinion whatsoever on the part of Research Square concerning the legal status of any country, territory, city or area or of its authorities, or concerning the delimitation of its frontiers or boundaries. This map has been provided by the authors.

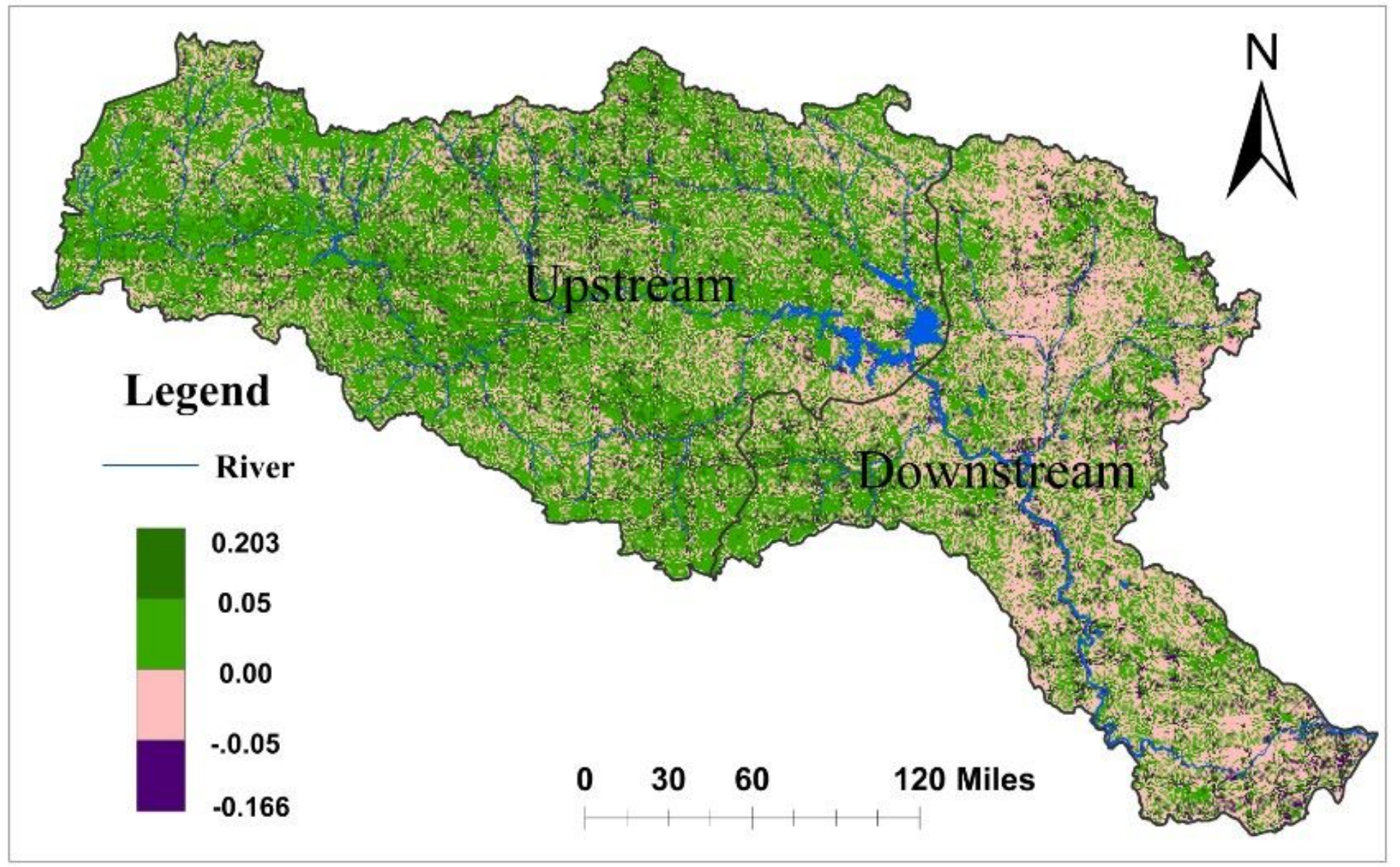




\section{Figure 8}

Spatial distribution of the residual mean from 1982 to 2018 (The map was created using ESRI ArcGIS 10.3, http://www.esri.com/sofware/arcgis/arcgis-for-desktop). Note: The designations employed and the presentation of the material on this map do not imply the expression of any opinion whatsoever on the part of Research Square concerning the legal status of any country, territory, city or area or of its authorities, or concerning the delimitation of its frontiers or boundaries. This map has been provided by the authors.

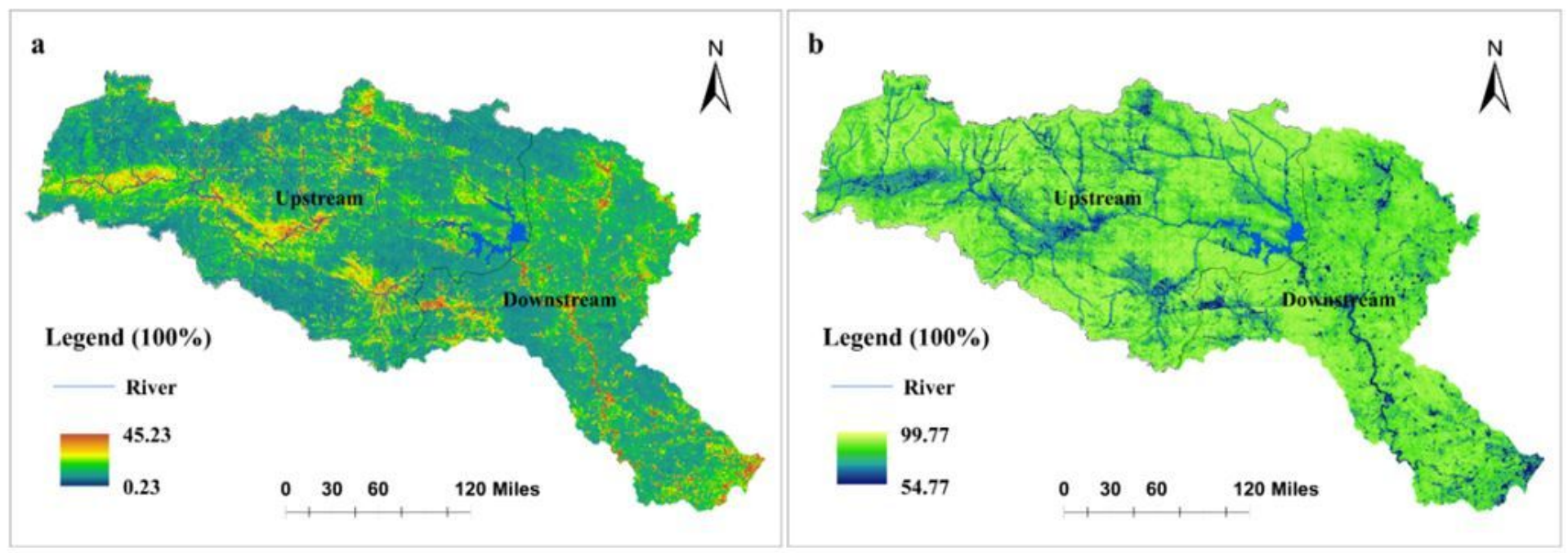

\section{Figure 9}

a) Spatial distribution of the average comprehensive contribution of residual from 1982 to 2018 ; b) Spatial distribution of the average comprehensive contribution of climate factors from 1982 to 2018. (The map was created using ESRI ArcGIS 10.3, http://www.esri.com/sofware/arcgis/arcgis-for-desktop). Note: The designations employed and the presentation of the material on this map do not imply the expression of any opinion whatsoever on the part of Research Square concerning the legal status of any country, territory, city or area or of its authorities, or concerning the delimitation of its frontiers or boundaries. This map has been provided by the authors.
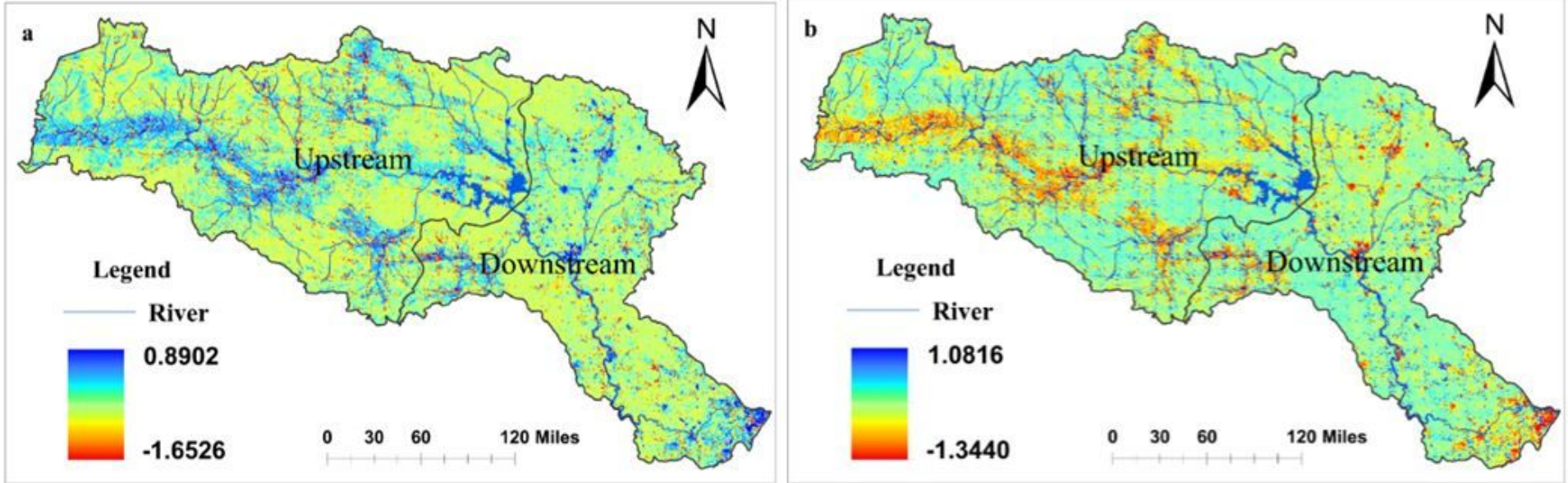
a) Spatial variation trend of the comprehensive contribution degree of residual from 1982 to 2018; b) Spatial variation trend of the comprehensive contribution degree of climate factors from 1982 to 2018 (The map was created using ESRI ArcGIS 10.3, http://www.esri.com/sofware/arcgis/arcgis-for-desktop). Note: The designations employed and the presentation of the material on this map do not imply the expression of any opinion whatsoever on the part of Research Square concerning the legal status of any country, territory, city or area or of its authorities, or concerning the delimitation of its frontiers or boundaries. This map has been provided by the authors.

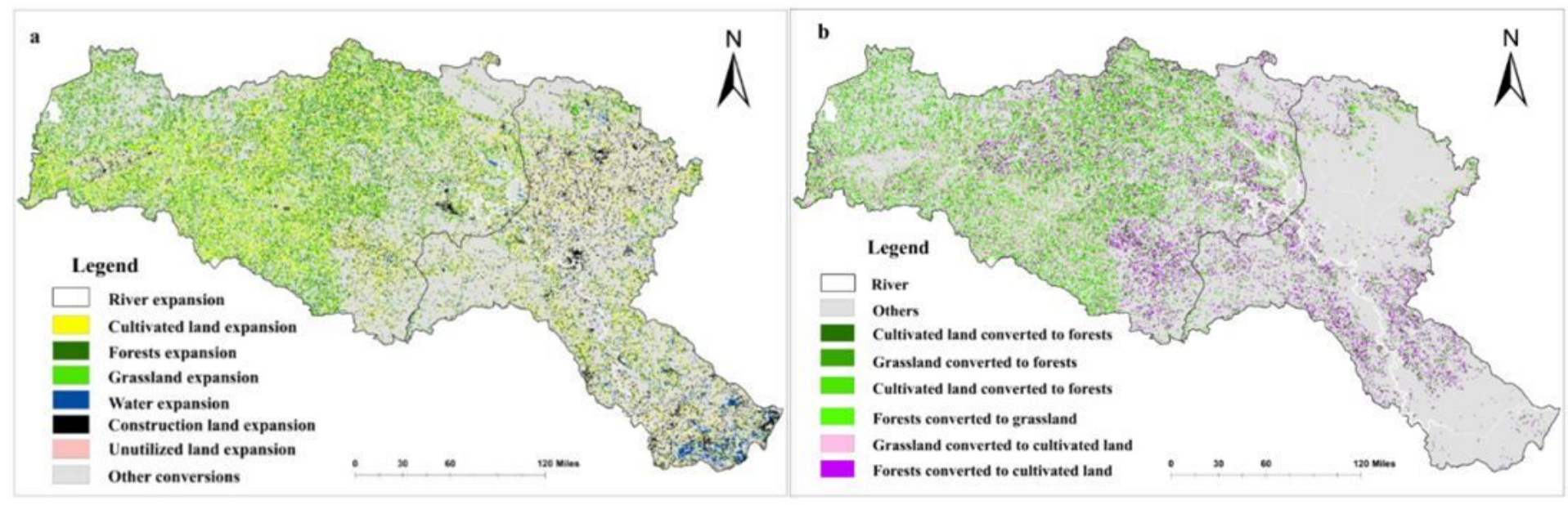

\section{Figure 11}

a) Expanded area of different land use types from 1980 to 2018; b) Conversion of cultivated land, forests and grassland from 1980 to 2018 (The map was created using ESRI ArcGIS 10.3, http://www.esri.com/sofware/arcgis/arcgis-for-desktop). Note: The designations employed and the presentation of the material on this map do not imply the expression of any opinion whatsoever on the part of Research Square concerning the legal status of any country, territory, city or area or of its authorities, or concerning the delimitation of its frontiers or boundaries. This map has been provided by the authors. 